\title{
Metabolic Control of Viral Infection through PPAR- $\alpha$ Regulation of STING Signaling
} interferon production is regulated by ROS. A. Reese R,2* $^{*}$ 75390, USA 75390, USA

${ }^{*}$ corresponding author

\section{Abstract}

Lili Tao ${ }^{1}$, Alexandria Lowe ${ }^{1}$, Guoxun Wang ${ }^{1}$, Igor Dozmorov ${ }^{1}$, Tyron Chang ${ }^{1}$, Nan Yan ${ }^{1,2}$, Tiffany

${ }^{1}$ Department of Immunology, University of Texas Southwestern Medical Center, Dallas, TX,

${ }^{2}$ Department of Microbiology, University of Texas Southwestern Medical Center, Dallas, TX,

Peroxisomal proliferator activated receptors (PPARs) are sensors of dietary lipids and pharmacological targets in the treatment of metabolic disorders. PPAR ligands are also immunosuppressive. However, their function during infection is debated and the mechanisms that underlie their immunoregulatory properties are unclear. We investigated the consequences of PPAR activation during herpesvirus infection. We found that activation of PPAR- $\alpha$ increased herpesvirus replication, suppressed type I interferon production and induced reactive oxygen species (ROS). We discovered that ROS induced by PPAR- $\alpha$ stimulation suppressed the cytoplasmic DNA sensing pathway after direct activation of stimulator of interferon (STING), the ER adapter downstream of cytoplasmic DNA recognition. Although high ROS induces inflammasome activation and cytokine production, we found that ROS inhibited interferon production after cytoplasmic DNA recognition. Treatment of mice with a clinically relevant agonist of PPAR- $\alpha$ increased herpesvirus replication and pathogenesis, comparable to levels observed previously in type I interferon receptor knockout mice. These findings reveal that activation of PPAR- $\alpha$ regulates immunity to cytoplasmic DNA and DNA virus infection through inhibition of interferon. Moreover, these results demonstrate that STING signaling and 


\section{Introduction}

Peroxisome proliferator activated receptors (PPARs) are ligand activated nuclear receptors that regulate fatty acid oxidation and cholesterol metabolism. The PPAR family

37 consists of three isoforms: PPAR- $\alpha$, PPAR- $\beta / \delta$, and PPAR- $\gamma$. All three receptors regulate lipid

38 homeostasis, although they differ in terms of their tissue distribution, ligand specificities, and

39 gene targets ${ }^{1}$. There are many natural and synthetic ligands of PPARs that are used to treat

40 dyslipidemia and glucose disorders. Natural ligands include dietary lipids, such as omega-3

41 polyunsaturated fatty acids found in fish oil, and immune mediators, such as eicosanoids.

42 Synthetic ligands, including fibrates that target PPAR- $\alpha$ and thiazolidinediones that target

43 PPAR- $\gamma$, are used to treat metabolic disorders ${ }^{1,2}$.

44 In addition to their role in metabolism, PPARs regulate inflammation. PPAR agonists

45 reduce inflammation in atherosclerosis, diabetes, neurodegenerative diseases, and autoimmune

46 diseases ${ }^{3}$. Their mechanisms of action are diverse and include repression of NFKB and AP-1

47 DNA binding, regulation of nitric oxide, inhibition of dendritic cell maturation, reduction of

48 cytokine expression by effector T cells, and inhibition of leukocyte recruitment to sites of

49 inflammation ${ }^{4,5}$. Despite their immunosuppressive function, the effects of PPAR agonists on

50 infectious disease outcomes has not been extensively studied. There are contradictory reports

51 that synthetic agonists or dietary lipids improve or impair resistance to pathogen challenge, but

52 we do not know the molecular mechanisms of PPAR-mediate immunoregulation during infection $53 \quad 6-10$.

Intermediates of cellular metabolism are important signaling molecules that alter immune

55 defense pathways ${ }^{11}$. PPARs, as their name implies, increase peroxisomal metabolism.

56 Peroxisomes synthesize phospholipids and bile acids and oxidize very long, branched chain,

57 and polyunsaturated fatty acids. They also produce significant amounts of hydrogen peroxide 
58 and other reactive oxygen species (ROS). ROS have been widely implicated in inflammatory

59 processes, particularly for NFאB signaling and inflammasome activation ${ }^{12}$. In general,

60 antioxidant treatment reduces inflammatory cytokines and interferon- $\beta$ (IFN $\beta$ ) after stimulation

61 with toll-like receptor agonists or viral RNA ${ }^{13-16}$. However, it is unclear whether peroxisomal

62 metabolism and ROS function in antiviral immunity to DNA viruses and cytoplasmic DNA.

Herpesviruses manipulate metabolism during infection to promote viral replication and

64 chronic infection ${ }^{17,18}$. In addition to altering glucose metabolism, herpesviruses induce

65 peroxisome proliferation ${ }^{19,20}$. Moreover, they encode viral proteins that target peroxisomes,

66 suggesting that modulation of peroxisomal function is important for these viruses ${ }^{21-23}$.

67 Here we investigated the consequences of activation of PPARs and peroxisomal

68 metabolism on herpesvirus infection and induction of antiviral immune responses. We

69 compared agonists for the three different PPARs and found that activation of PPAR- $\alpha$ increased

70 herpesvirus replication. PPAR- $\alpha$ stimulation inhibited type I interferon production following

71 DNA-virus infection or direct stimulation of the cyclic GMP-AMP synthase (cGAS)/stimulator of

72 interferon (STING) pathway. Importantly, treatment of mice with PPAR- $\alpha$ agonist led to

73 increased herpesvirus replication and heightened lethality in agonist-treated mice. Our data

74 suggest that activation of PPAR- $\alpha$ suppresses cytoplasmic DNA sensing by generating high

75 ROS that inhibit STING activation, leading to reduced type I interferon and impaired immunity to 76 viral infections.

78 Results

79 Activation of PPAR- $\alpha$ promotes MHV68 replication. 
83 phases of infections similar to human herpesvirus, such as Kaposi's sarcoma associated

84 herpesvirus (KSHV) and Epstein Barr virus (EBV) ${ }^{24-26}$. We treated bone marrow derived

85 macrophages with PPAR- $\alpha$ agonists, fenofibrate or WY14643, PPAR- $\beta / \delta$ agonist GW501516, or

86 PPAR- $\gamma$ agonist rosiglitazone. Following pretreatment, cells were infected with MHV68. We

87 examined expression of lytic viral proteins on infected cells by flow cytometry to assay for viral

88 replication ${ }^{25}$. We found that PPAR- $\alpha$ agonists fenofibrate and WY14643 both increased

89 expression of lytic viral proteins on infected macrophages compared with untreated cells or cells

90 treated with GW501516 or rosiglitazone (Figure 1a). MHV68 replication at either low or high

91 multiplicity of infection (MOI) was also increased in macrophages treated with fenofibrate or

92 WY14643 compared with untreated cells (Figure 1b, c, Supplemental Figure 1). Treatment with

93 agonist had no effect on virus replication in macrophages isolated from Ppara ${ }^{-/}$mice,

94 suggesting that PPAR- $\alpha$ is critical for agonist effects (Figure 1d). We tested whether stimulation

95 of PPAR- $\alpha$ affected replication of another herpesvirus that also infects macrophages and found

96 that replication of murine cytomegalovirus (MCMV) was also increased by PPAR- $\alpha$ agonist

97 (Supplemental Figure 2). Thus, PPAR- $\alpha$ stimulation increases herpesvirus replication in a

98 PPAR- $\alpha$-dependent manner.

PPAR- $\alpha$ stimulation suppresses type I IFN production in a STING-dependent manner

To broadly assess the impact of PPAR- $\alpha$ agonist on cells infected with virus, we performed RNA sequencing analysis on macrophages infected with virus and treated with

104 WY14643. Six hours after infection, uninfected/vehicle treated, MHV68+/vehicle treated, uninfected/WY14643 treated cells, and MHV68+/WY14643 treated macrophages were prepared for RNA-seq. Pathway analysis of differentially expressed genes revealed that virus infection in 107 both vehicle-treated and WY14643-treated cells increased expression of interferon responsive 


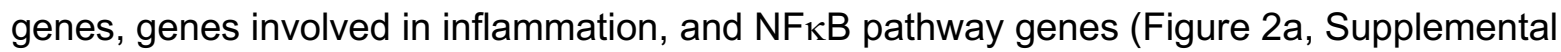

109 Table 1). However, PPAR- $\alpha$ stimulation reduced the magnitude of upregulation in infected cells.

110 Thus, PPAR- $\alpha$ stimulation attenuates the early antiviral response in infected cells.

To confirm the sequencing results, we quantified expression of a subset of interferon

112 stimulated genes. We measured Isg20, Isg15, and Cxc/10 and confirmed that expression of

113 these genes is reduced in both uninfected and infected macrophages treated with WY14643

114 (Figure 2b). We also measured expression of Ifnb and found that expression is reduced after

115 agonist treatment (Figure 2b). These data suggest that PPAR- $\alpha$ stimulation suppresses the 116 interferon response at baseline and after viral infection.

Because of the suppression of the early antiviral response, we tested whether the effects

121 stimulation did not further increase virus replication in the knockout cells (Supplemental Figure

122 3). Thus, PPAR- $\alpha$ stimulation effects depend on type I interferon.

MHV68 is a DNA virus that induces interferon downstream of the cGAS/STING pathway;

124 therefore, we hypothesized that PPAR- $\alpha$ stimulation could antagonize the early induction of

125 interferon after recognition of cytoplasmic DNA. Cytoplasmic DNA is sensed by cGAS, leading

126 to activation of endoplasmic reticulum adapter molecule STING. STING phosphorylates TBK1

127 and IRF3, leading to transcription of IFN $\beta$. IFN $\beta$ then signals through the type I IFN receptor to

128 induce interferon stimulated gene expression and more IFN $\beta$ expression. To test if PPAR- $\alpha$

129 stimulation could suppress IFN $\beta$ induction after direct activation of STING, macrophages were

130 treated with vehicle or agonist and stimulated with DMXAA, a murine agonist of STING. We

131 found that PPAR- $\alpha$ stimulation suppressed IFN $\beta$ expression after DMXAA transfection (Figure

132 2c). As expected, the PPAR- $\gamma$ and PPAR- $\delta$ agonists rosiglitazone and GW501516 did not 
133 suppress IFN $\beta$ expression after DMXAA treatment (Supplemental Figure 4). Moreover, PPAR- $\alpha$

134 stimulation suppressed production of IFN $\beta$ protein (Figure $2 \mathrm{~d}$ ). These data suggest that PPAR-

$135 \alpha$ stimulation antagonizes the induction of interferon production downstream of the STING DNA

136 sensing pathway.

137 To test if suppression of IFN $\beta$ depended on STING, we treated Sting ${ }^{-/-}$macrophages

138 with PPAR- $\alpha$ agonist and infected with MHV68. We found that PPAR- $\alpha$ stimulation no longer

139 increased virus replication in cells deficient in STING (Figure 2e). We examined activation of

140 TBK1 and IRF3 and found that PPAR- $\alpha$ stimulation suppressed DMXAA-induced

141 phosphorylation of both proteins (Figure 2f). These data indicate that the effects of PPAR- $\alpha$

142 agonist depend on STING expression and suggest that PPAR- $\alpha$ stimulation antagonizes the

143 initial induction of IFN $\beta$ after recognition of cytoplasmic DNA.

PPAR- $\alpha$ stimulation induces oxidative stress

We wondered if PPAR- $\alpha$ agonist effects could promote virus replication even if cells

148 were treated with agonist after infection, or if the effects of agonist required pretreatment. To

149 test this, we compared three different treatment protocols. We pretreated, as above, with

150 PPAR- $\alpha$ agonist overnight and replaced agonist in the media following infection with MHV68.

151 We compared this with pretreatment only (pre) or post treatment only (post). We found that

152 pretreatment with PPAR- $\alpha$ agonist was required to increase MHV68 replication (Figure 3a). We

153 found no increase in virus replication when cells were treated post-infection with agonist. We

154 also found that pretreatment alone was sufficient to increase virus replication. These data

155 suggest that PPAR- $\alpha$ stimulation is altering the cellular environment prior to infection in such a

156 way that enhances virus replication. 
In order to determine how PPAR- $\alpha$ stimulation was altering the cellular environment to

158 promote virus replication and impair interferon induction, we examined vehicle and WY14643-

159 only treatments from our sequencing data. PPAR- $\alpha$ agonist treated cells displayed increased

160 antioxidant response pathways, indicating a possible increase in oxidative stress in PPAR- $\alpha$

161 agonist treated cells (Figure 3b, Supplemental Table 2). To confirm these results, we analyzed

162 expression of antioxidant genes in untreated or PPAR- $\alpha$ agonist treated macrophages and

163 confirmed increased expression of Mgst1, Gsr, Slc7a11, Gstm1, Gclm, and Cd36 in agonist

164 treated cells (Figure 3c). PPAR- $\alpha$ agonist treatment of macrophages also promoted increase

165 total ROS (Figure 3d). These results are comparable to previous data indicating that PPAR- $\alpha$

166 agonist treatment increases $\beta$-oxidation of fatty acids in peroxisomes and enhances production

167 of $\operatorname{ROS}^{27,28}$.

Given that PPAR- $\alpha$ stimulation increased antioxidant gene expression and ROS

production and that these effects correlated with increased viral replication, we next tested

171 hydrogen peroxide $\left(\mathrm{H}_{2} \mathrm{O}_{2}\right)$ and stimulated with DMXAA. $\mathrm{H}_{2} \mathrm{O}_{2}$ treatment suppressed DMXAA-

172 induced IFN $\beta$ production (Figure 3e). In addition, N-Acetyl-L-cysteine (NAC), an antioxidant,

173 partially neutralized the effects of $\mathrm{H}_{2} \mathrm{O}_{2}$ (Figure $3 e$ ). $\mathrm{H}_{2} \mathrm{O}_{2}$ treatment suppressed

174 phosphorylation of TBK1 and IRF3 (Figure 3f). This indicates that increased oxidative stress

175 suppresses the cGAS/STING pathway after activation with cytoplasmic DNA.

To determine if cells that have constitutive high levels of ROS have impaired interferon

177 responses, we examined that antiviral response in nuclear factor E2-related factor 2 (NRF2)

178 deficient cells. NRF2 is a transcription factor that regulates antioxidant responses by binding to

179 antioxidant response elements (ARE) found in promoters of detoxication enzymes. NRF2

180 activity is regulated by KEAP1, and KEAP1 under non-stressed conditions promotes NRF2

181 ubiquitylation. When cells are under oxidative stress, NRF2 is released from KEAP1 and drives 
182 antioxidant gene expression ${ }^{29}$. Nrf2 ${ }^{-/}$cells do not induce antioxidant genes and have high

183 levels of ROS ${ }^{30-32}$. We confirmed that $\mathrm{Nrf2}^{-/-}$macrophages had increased ROS (Figure $3 \mathrm{~g}$ ).

184 When we stimulated $\mathrm{Nrf}^{-/-}$macrophages with DMXAA they induced less Ifnb expression

185 compared to wildtype cells (Figure 3H). Additionally, PPAR- $\alpha$ agonists did not further suppress

186 Ifnb transcript production from knockout cells (Figure 3h). Together, these data suggest that

187 ROS can suppress IFN $\beta$ downstream of direct STING activation.

To determine if the lower levels of IFN $\beta$ expressed in $\mathrm{Nrf}^{-/-}$macrophages led to

189 increased viral replication, we infected $\mathrm{Nrf2}^{---}$and wildtype macrophages with MHV68. We

190 observed increase viral protein expression after infection in $\mathrm{Nrf2}^{-/-}$macrophages, indicating that

191 virus replicated better in cells with higher levels of ROS and decreased IFN $\beta$ (Figure 3i).

PPAR- $\alpha$ stimulation increases virus replication and lethality in mice.

Because we found that PPAR- $\alpha$ stimulation in vitro suppressed interferon production, we hypothesized that agonist treatment of mice infected with MHV68 would alter herpesvirus

197 replication. Previously published work established that mice deficient in the IFN $\alpha / \beta$ receptor 198 (IFNAR) have increased viral replication and enhanced susceptibility to MHV68 ${ }^{33}$. To determine if PPAR- $\alpha$ stimulation increased MHV68 replication in vivo, we injected wildtype and 200 Ppara ${ }^{-/}$mice with WY14643 or vehicle control for 7 days, starting 3 days prior to infection and 201 continuing for 4 days after infection (Figure 4a). Mice were infected with a dose of MHV68 that 202 does not cause lethality in wildtype mice treated with the drug vehicle. However, wildtype mice 203 injected with PPAR- $\alpha$ agonist succumbed to infection (Figure 4b), at a frequency similar to type I 204 interferon receptor deficient mice ${ }^{33}$. Moreover, Ppara ${ }^{-/}$mice treated with agonist or vehicle all 205 survived infection with MHV68, indicating that the lethality observed in wildtype mice treated with agonist is PPAR- $\alpha$ dependent (Figure 4c). Using a luciferase-tagged MHV68 (MHV68- 
207 M3FL) we imaged mice infected with virus over multiple days during acute infection ${ }^{25,34}$. We

208 found that mice treated with WY14643 had increased virus replication compared to vehicle

209 treated mice, and that this increase in virus replication was PPAR- $\alpha$ dependent (Figure 4d, e).

210 These data suggest that PPAR- $\alpha$ stimulation significantly increased MHV68 acute replication.

211 To determine if the interferon response was altered by PPAR- $\alpha$ stimulation, we analyzed

212 interferon stimulated gene expression in the peritoneal cells for vehicle-treated and agonist-

213 treated mice. We found that expression of $I s g 20$ and $C x c / 10$ was decreased in agonist treated

214 mice (Figure 4f), indicated that treatment with PPAR- $\alpha$ agonist during acute infection

215 suppressed the interferon response.

\section{Discussion}

We determined that activation of PPAR- $\alpha$ with clinically relevant agonists increases

220 herpesvirus replication. In macrophages, PPAR- $\alpha$ stimulation increased virus replication and

221 suppressed the induction of an interferon response in a STING-dependent manner. PPAR- $\alpha$

222 stimulation induced oxidative stress in cells and high levels of oxidative stress impaired STING

223 activation. This is the first evidence that PPAR- $\alpha$ activation and peroxisomal metabolism

224 regulate the cytoplasmic DNA-sensing pathway and IFN $\beta$ production downstream of STING.

225 PPAR- $\alpha$ stimulation significantly increased herpesvirus replication in mice, leading to increased 226 lethality of agonist-treated mice.

227 Metabolism is recognized as an important regulator of immunity. Metabolic

228 reprogramming of macrophages, in particular, is essential for modifying their inflammatory

229 phenotype and function. Glycolysis drives inflammatory macrophage responses, whereas high

230 fatty acid oxidation was long thought to support anti-inflammatory macrophage responses ${ }^{35}$. It

231 is now clear that fatty acid oxidation is not just anti-inflammatory, because oxidation of palmitate 
232 promotes the production of mitochondrial ROS, which induces inflammasome activation ${ }^{36,37}$.

233 Moreover, mitochondrial ROS promotes the production of the proinflammatory cytokines IL-1 $\beta$,

234 IL-6, and TNF $\alpha$ following LPS stimulation of macrophages ${ }^{38}$. Our data adds another level of

235 complexity to the role of ROS in inflammation. Our data indicates that ROS, perhaps derived

236 from peroxisomal $\beta$-oxidation of very long chain fatty acids or other sources, impairs STING

237 activation and interferon production. Further work is needed to determine the source of ROS.

238 However, our data thus far suggests that the induction of peroxisomal metabolism and fatty acid 239 oxidation impairs innate immune signaling.

240 These data reveal that peroxisomal metabolism and increased ROS production

241 regulates the cytoplasmic DNA sensing pathway. The adapter molecule MAVS that signals

242 downstream of RNA recognition is localized to mitochondria and peroxisomes. Interestingly, the

243 peroxisomal localization of MAVS dictates unique signaling pathways and gene responses

244 distinct from mitochondrial MAVS ${ }^{39,40}$. Together these data along with our data indicate that

245 peroxisomes are critical organelles for the induction of innate immune signals, either through

246 localization of signaling molecules or production of metabolites that regulate immune signaling.

247 Herpesviruses use multiple mechanisms to maintain chronic infections in the host and

248 peroxisomal metabolism is a putative mechanism. To avoid clearance, herpesviruses evade

249 immune recognition by downregulating antigen presentation, expressing viral proteins that

250 regulate the interferon pathway, inhibiting cell cycle arrest and apoptosis, and encoding various

251 molecular mimics. This is indicative of a long evolutionary relationship with the host. It also

252 suggests that herpesviruses modify numerous pathways within the host cell to tune the balance

253 between latency and reactivation. Peroxisomal proliferation is a feature of herpesvirus infection,

254 but the function of peroxisomal biogenesis during latency has been elusive. A recent report

255 found that HCMV and HSV-1 induced peroxisome biogenesis and plasmalogen production,

256 leading to enhanced virus envelopment and lytic replication ${ }^{20}$. However, these data do not 
257 address the potential role of peroxisome biogenesis in chronic infection with a herpesvirus.

258 KSHV latent cell survival requires peroxisomal lipid metabolism, suggesting that KSHV

259 regulates peroxisomal lipid metabolism to support latent infection ${ }^{19}$. One hypothesis is that

260 peroxisomes and the redox balance of the cell control latency by adjusting the production of

261 type I interferon.

262 A key remaining question is how ROS regulates STING activation. Recent structural

263 data provide numerous insights into the mechanism of cGAMP activation of STING ${ }^{41,42}$. STING

264 dimers in the ER form polymers upon binding to cGAMP and disulfide bonds in the cytosolic

265 domain stabilize STING polymers. These inter-dimer crosslinks are important for STING

266 activation. One possibility is that increased oxidative stress leads to oxidation of cysteine

267 residues in the cytosolic domain, which interferes with the polymerization and activation of

268 STING ${ }^{43}$.

269 Overall, our work suggests that activation of PPAR- $\alpha$ suppresses interferon and antiviral

270 immunity. Moreover, these data indicate that metabolism and particularly ROS have both

271 proinflammatory and anti-inflammatory functions. These results have implications for therapies

272 that target PPAR- $\alpha$ or oxidative stress pathways for the treatment of infection, metabolic

273 disorders, cancer and autoimmune disease.

274

\section{Acknowledgments}

276 We thank members of the Reese and Yan labs for technical assistance, David

277 Mangelsdorf and Steven Kleiwer for reagents and expertise, Dr. Wenhan Zhu for help with data

278 analysis, and Drs. Julie Pfeiffer and Lora Hooper for editorial assistance. We also thank the

279 UTSW Flow Cytometry core and the Genomic and Microarray core for technical assistance.

280 The Reese lab is supported by the American Heart Association (17SDG33670071), the NIH

281 (1R01Al130020-01A1), and the Pew Scholars Program. 


\section{Author Contributions}

284

L.T. performed and analyzed experiments, with technical assistance from A.L, G.W and

285 T.C. I.D. performed RNAseq analysis. N.Y. provided reagents and expertise. T.A.R. directed

286 the project and wrote the manuscript.

287

288 Declaration of Interests

289 The authors declare no competing interests.

290 


\section{Figure 1. PPAR- $\alpha$ stimulation increases MHV68 replication.}

292 a, Macrophages from C57BL6/J mice were pretreated for 16 hours with WY14643, fenofibrate, 293 rosiglitazone, or GW501516. Cells were infected with MHV68 at MOI=5. Quantification of cells 294 expressing MHV68 lytic proteins using a polyclonal antibody 24 hours after infection was 295 measured by flow cytometry. Data represents mean \pm SD from 5 independent experimental.

296 b-c, Growth curve of MHV68 in macrophages isolated from C57BL/6J mice after pretreatment

297 with vehicle, WY14643 or fenofibrate. Cells were infected with MHV68 at MOI=5 (b) or MOI=0.1

298 (c). Virus quantitated by plaque assay on 3 T12 cells. Data represents mean \pm SD from 3

299 independent experiments.

$300 \mathrm{~d}$, Growth curve of MHV68 in macrophages isolated from Ppara ${ }^{-/}$mice after pretreatment with 301 vehicle, WY14643 or fenofibrate. Cells were infected with MHV68 at MOI=5. Data represents 302 mean \pm SD from 3 independent experiments. 


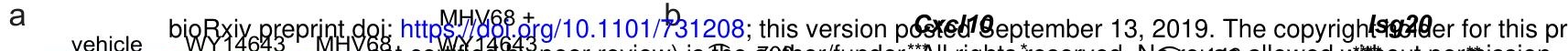
vehicle

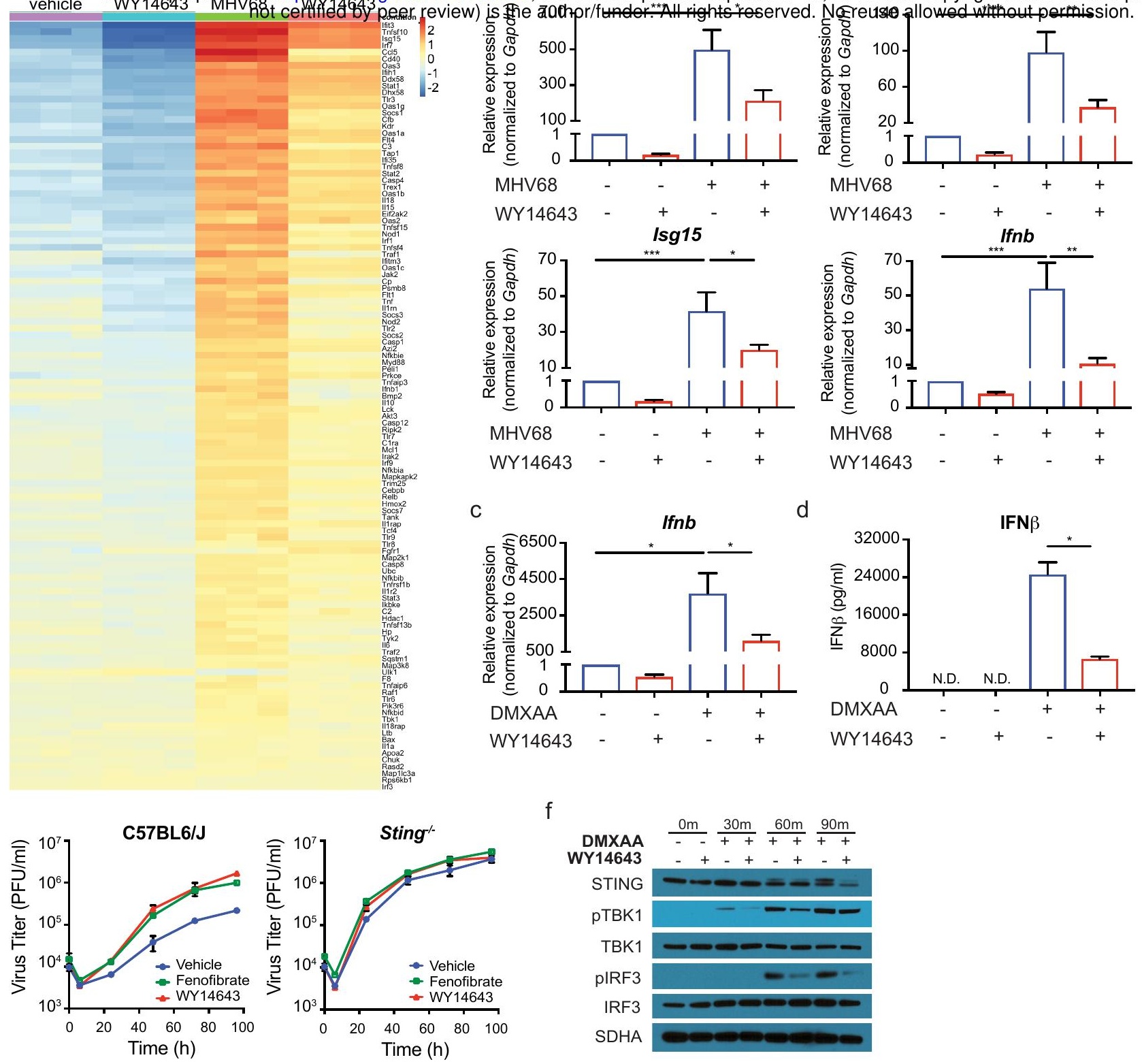



using one-way ANOVA test. Ifnb. determined by ELISA assay. $n=3$. $n=3$. after transfection with DMXAA.

Figure 2. PPAR- $\alpha$ stimulation suppresses type I IFN in a STING-dependent manner.

a, Macrophages were pretreated with vehicle or WY14643 for 16 hours prior to infection with MHV68, MOI=5. 6 hours after infection, RNA was isolated and prepared for RNA sequencing. b, Macrophages were pretreated with vehicle or WY14643 for 16 hours prior to infection with MHV68. qRT-PCR of Cxcl10, Isg20, Isg15 and Ifnb before and 6 hours after MHV68 infection. Relative expression normalized to Gapdh. $\mathrm{n}=5$ for $c x c / 10, \mathrm{n}=7$ for $/ \operatorname{sg} 20, \mathrm{n}=6$ for $I s g 15, \mathrm{n}=8$ for

c, Macrophages were pretreated with vehicle or WY14643 for 16 hours prior to transfection with DMXAA. qRT-PCR of Ifnb before and 2 hours after transfection with DMXAA. Relative expression normalized to Gapdh. $\mathrm{n}=9$.

d, Macrophages were pretreated with vehicle or WY14643 for 16 hours prior to transfection with DMXAA. Concentration of IFN $\beta$ in culture medium before and 24 hours after transfection was

e, Macrophages from C57BL6/J or Sting ${ }^{-/-}$mice were pretreated with vehicle or WY14643 for 16 hours prior to infection with MHV68, MOI=5. Virus growth was quantitated by plaque assay.

f, Macrophages were pretreated with vehicle or WY14643 for 16 hours. Representative western blot of proteins involved in STING signaling before transfection and 30 mins, 60 mins, 90 mins 
bioRxiv preprint doi: http\$//doi.org/10.1101/731208; this version posted September 1ॄ, 2019. The copyright holder for this pr
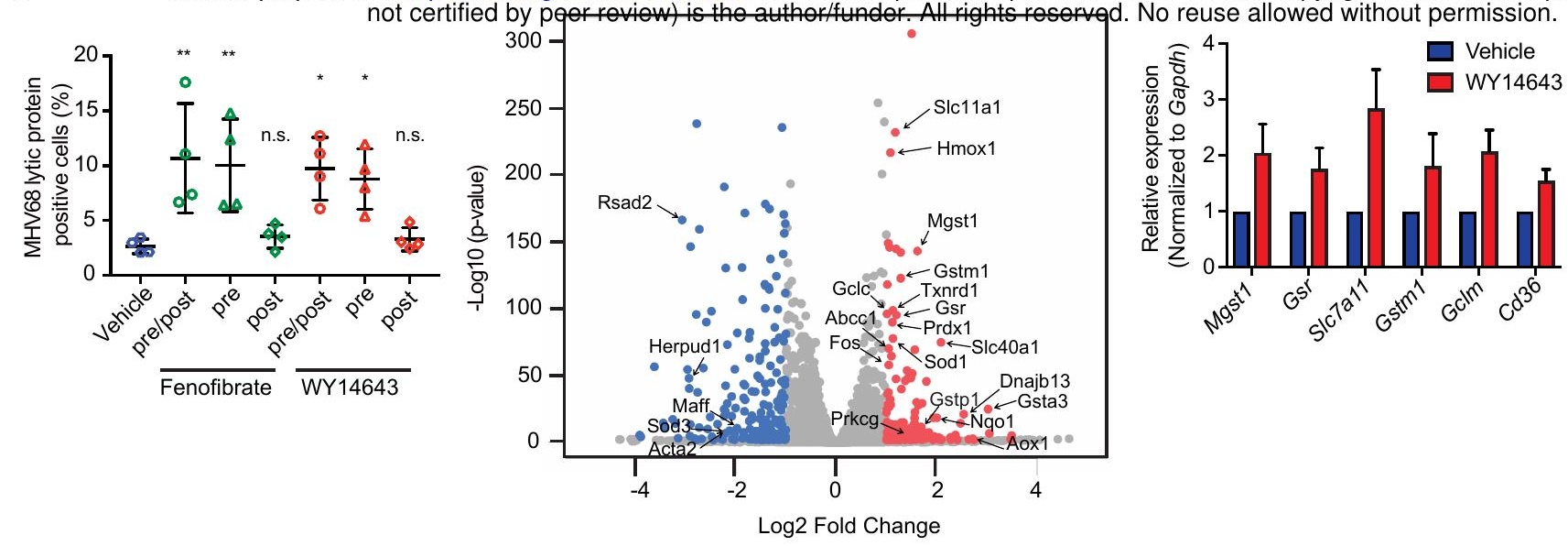

d

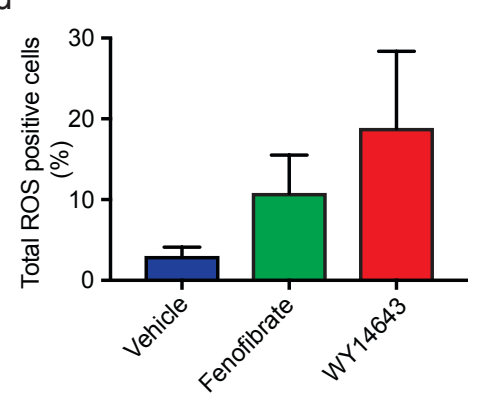

9

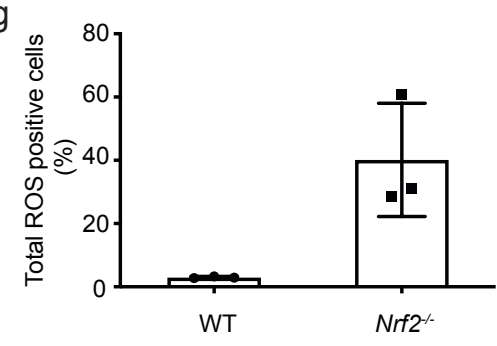

e

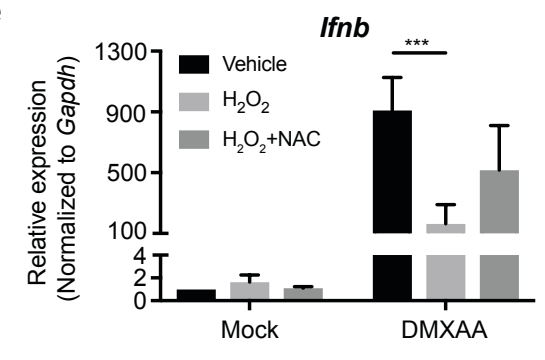

h

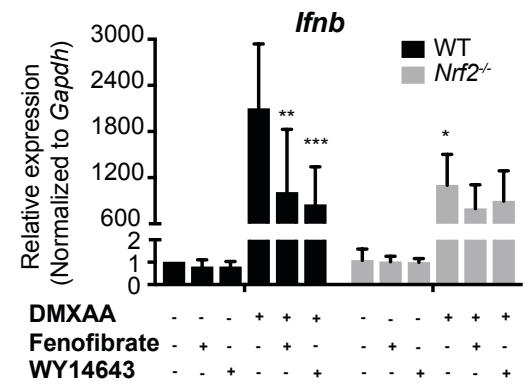

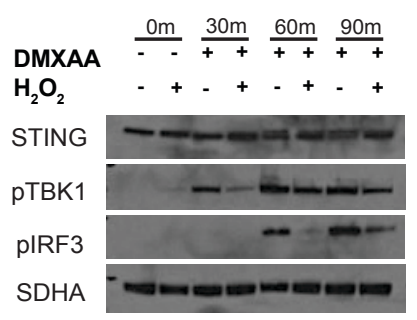

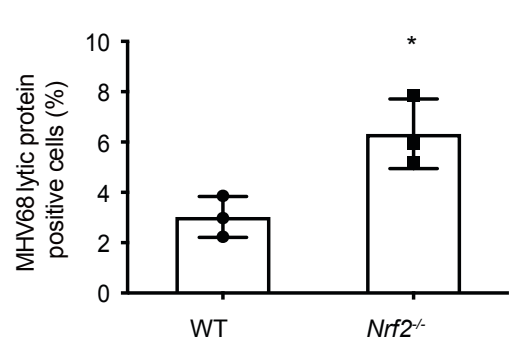


Figure 3. Oxidative stress inhibits STING activation and interferon production.

a, Macrophages were treated with vehicle, WY14643 or fenofibrate agonist pre and postinfection (pre/post), pre-infection only (pre) or post-infection only (post). Quantification of cells expressing MHV68 lytic proteins by FACs assay 24 hours after infection. $n=4$. analysis in Figure 2A.

334 c, Macrophages were treated with either vehicle control or WY14643 overnight. Genes

335 associated with oxidative stress response were quantitated by qRT-PCR. Relative expression

336 normalized to Gapdh. n=5 from independent experiments.

337 d, Macrophages were treated with vehicle, fenofibrate or WY14643 for 6 hours. Quantification

338 of total ROS in BMDMs by flow cytometry. $n=7$ with vehicle and fenofibrate treatment, $n=6$ with

339 WY14643 treatment.

340 e, Macrophages were pretreated with vehicle control or $\mathrm{H}_{2} \mathrm{O}_{2}$ for 20 mins. Half of the $\mathrm{H}_{2} \mathrm{O}_{2}$

341 samples were treated with NAC for 30 minutes and half were mock treated. Treatments were

342 replaced with fresh media and cells were transfected with DMXAA. After 2 hours Ifnb was

343 quantitated from lysates by qRT-PCR. $n=4$ from independent experiments.

$344 \mathrm{f}$, Macrophages were treated with either vehicle or $\mathrm{H}_{2} \mathrm{O}_{2}$ for 20 mins, and then transfected with

345 DMXAA. Expression of STING, phosphorylated TBK1 (pTBK1), phosphorylated IRF3 (pIRF3),

346 and SDHA was quantitated $0,30,60$ or 90 minutes after transfection. Representative of 3

347 separate experiments.

$348 \mathrm{~g}$, Macrophages were isolated from C57BL6/J or $\mathrm{Nrf2}^{-/-}$mice. Total ROS was quantitated by flow 349 cytometry. $n=3$ from independent experiments.

$350 \mathrm{~h}$, Macrophages isolated from WT or Nrf2-/ mice were pretreated for 16 hours with fenofibrate, 351 WY14643, or vehicle. Cells were transfected with DMXAA and expression of Ifnb transcript was 352 quantitated 2 hours later. Relative expression of Ifnb was normalized to Gapdh. $\mathrm{n}=5$ 
353 Data all shown as mean $\pm \mathrm{SD} ;{ }^{*} \mathrm{p}<0.05,{ }^{* *} \mathrm{p}<0.01,{ }^{* * *} \mathrm{P}<0.001$, statistical analysis was conducted

354 using one-way ANOVA or two-way ANOVA test.

355 i, Macrophages isolated from WT or Nrf2-/ mice were infected with MHV68 at a MOI=5 for 24

356 hours. Cells expressing MHV68 lytic proteins were quantified by FACs assay. N=3 from

357 independent experiments.

358 Data all shown as mean $\pm \mathrm{SD} ;{ }^{*} p<0.05,{ }^{* *} p<0.01$, statistical analysis was conducted using one359 way ANOVA or unpaired t-test. 
bioRxiv preprint doi: httiss://doi.org/10.1101/731208; this version posted September 13, 2019. The copyright holder for this pr

a Acute Replication Expts. not certified by peer review) ibl/fe author/funder. All Yights reserved. No revispantarved without permission. MHV68-M3FL $10^{6}$ pfu i.p. $\downarrow$

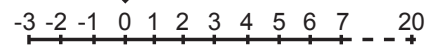

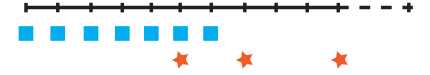
WY14643 or vehicle
* image
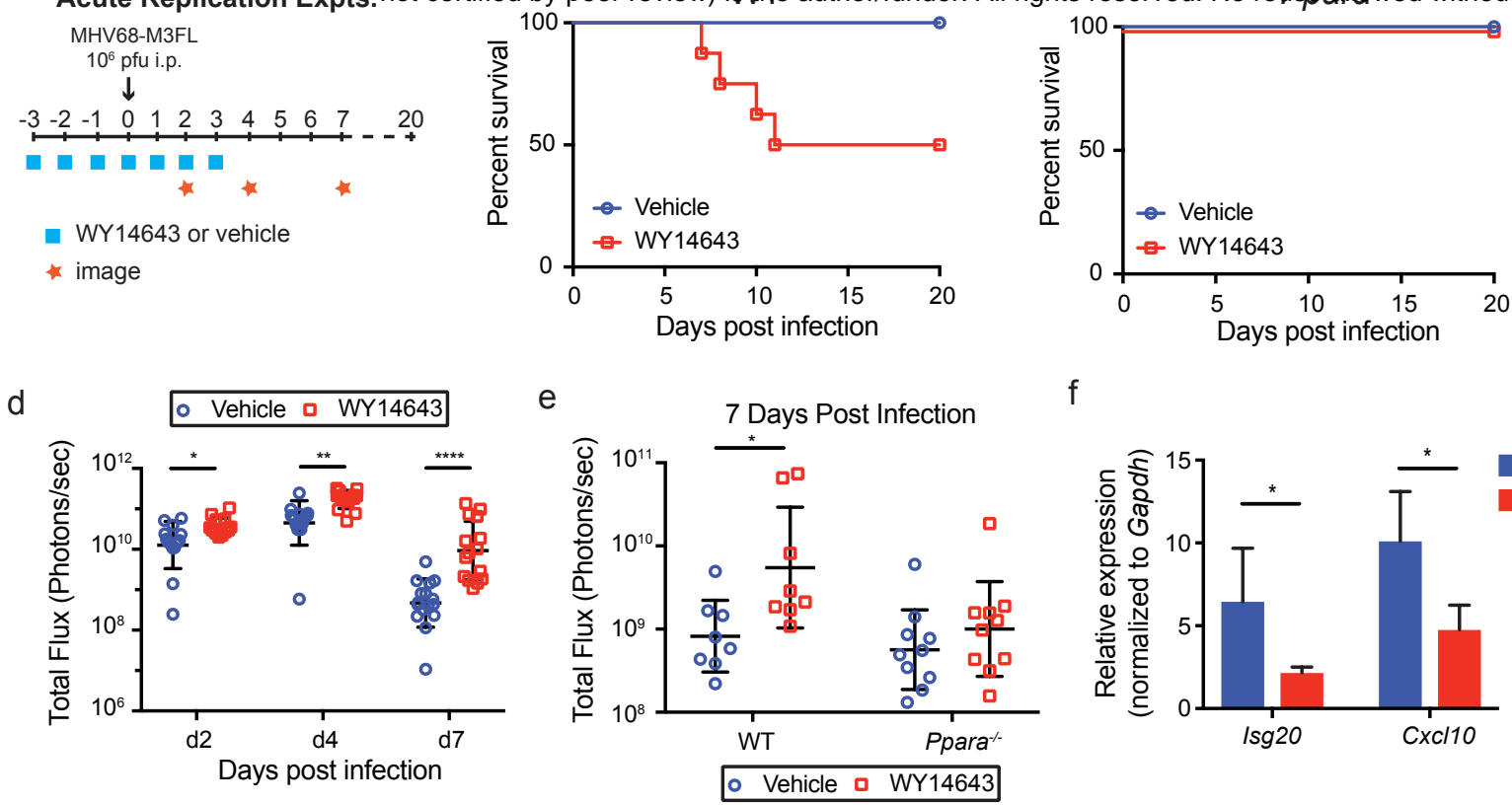
$\mathrm{f}$

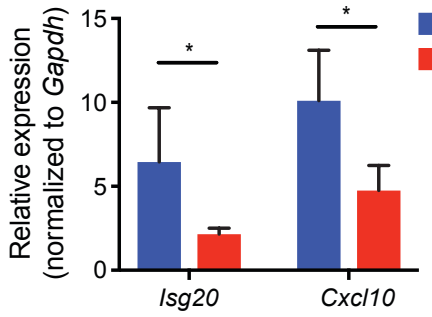




\section{Figure 4. PPAR- $\alpha$ stimulation in mice increases virus replication and lethality.}

362 a, Schematic for acute replication of MHV68 in mice. Mice were treated with either vehicle 363 control (15\% HS15) or WY14643 (100 mg/kg) for 7 days, starting 3 days before infection. Mice 364 were infected intraperitoneally with MHV68-M3FL at dose of $10^{6} \mathrm{PFU}$. Acute replication of virus 365 was measured at d2, d4 and d7 after infection using an IVIS bioluminescent imager. Survival of 366 mice was monitored until 20 days after infection.

367 b-c, Survival of mice infected with MHV68. C57BL6/J (b) or Ppara ${ }^{-/}$(c) mice were treated with 368 either vehicle control or WY14643, and infected with MHV68. $n=8$ in each group of C57BL6/J 369 mice, $\mathrm{n}=10$ in each group of Ppara $^{-/}$mice. Data shown as the pool of 2 independent 370 experiments.

$371 \mathrm{~d}$, Acute replication of MHV68 in mice measured by luminescent intensity. $\mathrm{n}=16$ in vehicle

372 treatment group, $n=15$ in WY14643 treatment group, data shown as the pool of 3 independent 373 experiments.

374 e, Acute replication of MHV68 in WT or Ppara ${ }^{-/}$mice measured by luminescent intensity. $n=8$ in

375 each group of WT mice, $n=10$ in each group of Ppara ${ }^{-/}$mice. Data shown as the pool of 2

376 independent experiments.

377 f, Peritoneal exudate cells were collected from vehicle or WY14643-treated mice 2 days after 378 infection with MHV68. Relative expression of Isg20 and $\mathrm{Cxcl10}$ was quantitated and normalized 379 to Gapdh. n=4 from 2 independent experiments.

380 Data all shown as mean $\pm \mathrm{SD} ;{ }^{*} \mathrm{p}<0.05,{ }^{* *} \mathrm{p}<0.01,{ }^{* * *} \mathrm{P}<0.001$, statistical analysis was conducted 381 using one-way ANOVA or two-way repeated measures ANOVA test. 


\section{References}

1. Grygiel-Górniak, B. Peroxisome proliferator-activated receptors and their ligands: nutritional and clinical implications--a review. Nutrition journal 13, 17 (2014).

2. Staels, B. et al. Mechanism of action of fibrates on lipid and lipoprotein metabolism. Circulation 98, 2088-2093 (1998).

3. Staels, B. \& Fruchart, J.-C. C. Therapeutic roles of peroxisome proliferator-activated receptor agonists. Diabetes 54, 2460-70 (2005).

4. Bensinger, S. J. \& Tontonoz, P. Integration of metabolism and inflammation by lipid-activated nuclear receptors. Nature 454, 470-477 (2008).

5. Straus, D. S. \& Glass, C. K. Anti-inflammatory actions of PPAR ligands: new insights on cellular and molecular mechanisms. Trends in immunology 28, 551-558 (2007).

6. Husson, M.-O. O. et al. Modulation of host defence against bacterial and viral infections by omega-3 polyunsaturated fatty acids. The Journal of infection 73, 523-535 (2016).

7. Jones, G. J. \& Roper, R. L. The effects of diets enriched in omega-3 polyunsaturated fatty acids on systemic vaccinia virus infection. Scientific reports 7, 15999 (2017).

8. Manoharan, I. et al. Homeostatic PPARa Signaling Limits Inflammatory Responses to Commensal Microbiota in the Intestine. Journal of immunology (Baltimore, Md. : 1950) 196, 4739-4749 (2016).

9. Anderson, M. \& Fritsche, K. L. (n-3) Fatty acids and infectious disease resistance. The Journal of nutrition 132, 3566-76 (2002).

10. Irons, R., Anderson, M. J., Zhang, M. \& Fritsche, K. L. Dietary fish oil impairs primary host resistance against Listeria monocytogenes more than the immunological memory response. The Journal of nutrition 133, 1163-9 (2003).

11. O'Neill, L. A., Kishton, R. J. \& Rathmell, J. A guide to immunometabolism for immunologists. Nature Reviews Immunology 16, 553-565 (2016).

12. Forrester, S. J., Kikuchi, D. S., Hernandes, M. S., Xu, Q. \& Griendling, K. K. Reactive Oxygen Species in Metabolic and Inflammatory Signaling. Circulation research 122, 877-902 (2018).

13. Soucy-Faulkner, A. et al. Requirement of NOX2 and reactive oxygen species for efficient RIG-I-mediated antiviral response through regulation of MAVS expression. PLoS pathogens 6, e1000930 (2010).

14. Kong, X., Thimmulappa, R., Kombairaju, P. \& Biswal, S. NADPH oxidase-dependent reactive oxygen species mediate amplified TLR4 signaling and sepsis-induced mortality in Nrf2deficient mice. Journal of immunology (Baltimore, Md. : 1950) 185, 569-77 (2010).

15. Kobayashi, E. H. et al. Nrf2 suppresses macrophage inflammatory response by blocking proinflammatory cytokine transcription. Nature communications 7, 11624 (2016). 
16. Agod, Z. et al. Regulation of type I interferon responses by mitochondria-derived reactive oxygen species in plasmacytoid dendritic cells. Redox biology 13, 633-645 (2017).

17. Yu, Y., Clippinger, A. J. \& Alwine, J. C. Viral effects on metabolism: changes in glucose and glutamine utilization during human cytomegalovirus infection. Trends in microbiology 19, 360367 (2011).

18. Vastag, L., Koyuncu, E., Grady, S. L., Shenk, T. E. \& Rabinowitz, J. D. Divergent effects of human cytomegalovirus and herpes simplex virus-1 on cellular metabolism. PLoS pathogens 7, e1002124 (2011).

19. Sychev, Z. E. et al. Integrated systems biology analysis of KSHV latent infection reveals viral induction and reliance on peroxisome mediated lipid metabolism. PLoS pathogens 13, e1006256 (2017).

20. Beltran, P. M. et al. Infection-Induced Peroxisome Biogenesis Is a Metabolic Strategy for Herpesvirus Replication. Cell host \& microbe 24, 526-541.e7 (2018).

21. Choi, Y. B., Choi, Y. \& Harhaj, E. W. Peroxisomes support human herpesvirus 8 latency by stabilizing the viral oncogenic protein VFLIP via the MAVS-TRAF complex. PLoS pathogens 14, e1007058 (2018).

22. Magalhães, A. C. et al. Peroxisomes are platforms for cytomegalovirus' evasion from the cellular immune response. Scientific reports 6, 26028 (2016).

23. Zheng, C. \& Su, C. Herpes simplex virus 1 infection dampens the immediate early antiviral innate immunity signaling from peroxisomes by tegument protein VP16. Virology journal 14, 35 (2017).

24. Barton, E., Mandal, P. \& Speck, S. H. Pathogenesis and host control of gammaherpesviruses: lessons from the mouse. Annual review of immunology 29, 351-397 (2011).

25. Reese, T. et al. Helminth infection reactivates latent $\mathrm{y}$-herpesvirus via cytokine competition at a viral promoter. Science 345, 573-577 (2014).

26. Reese, T. A. Co-infections: Another Variable in the Herpesvirus Latency-Reactivation Dynamic. Journal of virology 90, JVI.01865-15-5537 (2016).

27. Reddy, J. \& Hashimoto, T. Peroxisomal beta-oxidation and peroxisome proliferator-activated receptor alpha: an adaptive metabolic system. Annual review of nutrition 21, 193-230 (2001).

28. Teissier, E. et al. Peroxisome proliferator-activated receptor alpha induces NADPH oxidase activity in macrophages, leading to the generation of LDL with PPAR-alpha activation properties. Circulation research 95, 1174-82 (2004).

29. Nguyen, T., Nioi, P. \& Pickett, C. B. The Nrf2-antioxidant response element signaling pathway and its activation by oxidative stress. The Journal of biological chemistry 284, 13291-5 (2009). 
30. Chan, K., Lu, R., Chang, J. \& Kan, Y. NRF2, a member of the NFE2 family of transcription factors, is not essential for murine erythropoiesis, growth, and development. Proceedings of the National Academy of Sciences of the United States of America 93, 13943-8 (1996).

31. Itoh, K. et al. An Nrf2/small Maf heterodimer mediates the induction of phase II detoxifying enzyme genes through antioxidant response elements. Biochemical and biophysical research communications 236, 313-22 (1997).

32. McMahon, M. et al. The Cap'n'Collar basic leucine zipper transcription factor Nrf2 (NF-E2 p45-related factor 2) controls both constitutive and inducible expression of intestinal detoxification and glutathione biosynthetic enzymes. Cancer research 61, 3299-307 (2001).

33. Dutia, B., Allen, D., Dyson, H. \& Nash, A. Type I interferons and IRF-1 play a critical role in the control of a gammaherpesvirus infection. Virology 261, 173-179

34. Hwang, S. et al. Persistent gammaherpesvirus replication and dynamic interaction with the host in vivo. Journal of virology 82, 12498-12509 (2008).

35. den Bossche, J., O’Neill, L. A. \& Menon, D. Macrophage Immunometabolism: Where Are We (Going)? Trends in immunology 38, 395-406 (2017).

36. Hall, C. J. et al. Immunoresponsive gene 1 augments bactericidal activity of macrophagelineage cells by regulating $\beta$-oxidation-dependent mitochondrial ROS production. Cell metabolism 18, 265-78 (2013).

37. Moon, J.-S. S. et al. NOX4-dependent fatty acid oxidation promotes NLRP3 inflammasome activation in macrophages. Nature medicine 22, 1002-12 (2016).

38. Bulua, A. C. et al. Mitochondrial reactive oxygen species promote production of proinflammatory cytokines and are elevated in TNFR1-associated periodic syndrome (TRAPS). The Journal of experimental medicine 208, 519-33 (2011).

39. Dixit, E. et al. Peroxisomes are signaling platforms for antiviral innate immunity. Cell 141, 668-81 (2010).

40. Odendall, C. et al. Diverse intracellular pathogens activate type III interferon expression from peroxisomes. Nature immunology 15, 717-26 (2014).

41. Shang, G., Zhang, C., Chen, Z. J., Bai, X.-C. C. \& Zhang, X. Cryo-EM structures of STING reveal its mechanism of activation by cyclic GMP-AMP. Nature 567, 389-393 (2019).

42. Ergun, S. L., Fernandez, D., Weiss, T. M. \& Li, L. STING Polymer Structure Reveals Mechanisms for Activation, Hyperactivation, and Inhibition. Cell 178, 290-301.e10 (2019).

43. Jin, L., Lenz, L. L. \& Cambier, J. C. Cellular reactive oxygen species inhibit MPYS induction of IFNß. PloS one 5, e15142 (2010). 


\section{References}

1. Grygiel-Górniak, B. Peroxisome proliferator-activated receptors and their ligands: nutritional and clinical implications--a review. Nutrition journal 13, 17 (2014).

2. Staels, B. et al. Mechanism of action of fibrates on lipid and lipoprotein metabolism. Circulation 98, 2088-2093 (1998).

3. Staels, B. \& Fruchart, J.-C. C. Therapeutic roles of peroxisome proliferator-activated receptor agonists. Diabetes 54, 2460-70 (2005).

4. Bensinger, S. J. \& Tontonoz, P. Integration of metabolism and inflammation by lipid-activated nuclear receptors. Nature 454, 470-477 (2008).

5. Straus, D. S. \& Glass, C. K. Anti-inflammatory actions of PPAR ligands: new insights on cellular and molecular mechanisms. Trends in immunology 28, 551-558 (2007).

6. Husson, M.-O. O. et al. Modulation of host defence against bacterial and viral infections by omega-3 polyunsaturated fatty acids. The Journal of infection 73, 523-535 (2016).

7. Jones, G. J. \& Roper, R. L. The effects of diets enriched in omega-3 polyunsaturated fatty acids on systemic vaccinia virus infection. Scientific reports 7, 15999 (2017).

8. Manoharan, I. et al. Homeostatic PPARa Signaling Limits Inflammatory Responses to Commensal Microbiota in the Intestine. Journal of immunology (Baltimore, Md. : 1950) 196, 4739-4749 (2016).

9. Anderson, M. \& Fritsche, K. L. (n-3) Fatty acids and infectious disease resistance. The Journal of nutrition 132, 3566-76 (2002).

10. Irons, R., Anderson, M. J., Zhang, M. \& Fritsche, K. L. Dietary fish oil impairs primary host resistance against Listeria monocytogenes more than the immunological memory response. The Journal of nutrition 133, 1163-9 (2003).

11. O'Neill, L. A., Kishton, R. J. \& Rathmell, J. A guide to immunometabolism for immunologists. Nature Reviews Immunology 16, 553-565 (2016).

12. Forrester, S. J., Kikuchi, D. S., Hernandes, M. S., Xu, Q. \& Griendling, K. K. Reactive Oxygen Species in Metabolic and Inflammatory Signaling. Circulation research 122, 877-902 (2018).

13. Soucy-Faulkner, A. et al. Requirement of NOX2 and reactive oxygen species for efficient RIG-I-mediated antiviral response through regulation of MAVS expression. PLoS pathogens 6, e1000930 (2010).

14. Kong, X., Thimmulappa, R., Kombairaju, P. \& Biswal, S. NADPH oxidase-dependent reactive oxygen species mediate amplified TLR4 signaling and sepsis-induced mortality in Nrf2deficient mice. Journal of immunology (Baltimore, Md. : 1950) 185, 569-77 (2010).

15. Kobayashi, E. H. et al. Nrf2 suppresses macrophage inflammatory response by blocking proinflammatory cytokine transcription. Nature communications 7, 11624 (2016). 
16. Agod, Z. et al. Regulation of type I interferon responses by mitochondria-derived reactive oxygen species in plasmacytoid dendritic cells. Redox biology 13, 633-645 (2017).

17. Yu, Y., Clippinger, A. J. \& Alwine, J. C. Viral effects on metabolism: changes in glucose and glutamine utilization during human cytomegalovirus infection. Trends in microbiology 19, 360367 (2011).

18. Vastag, L., Koyuncu, E., Grady, S. L., Shenk, T. E. \& Rabinowitz, J. D. Divergent effects of human cytomegalovirus and herpes simplex virus-1 on cellular metabolism. PLoS pathogens 7, e1002124 (2011).

19. Sychev, Z. E. et al. Integrated systems biology analysis of KSHV latent infection reveals viral induction and reliance on peroxisome mediated lipid metabolism. PLoS pathogens 13, e1006256 (2017).

20. Beltran, P. M. et al. Infection-Induced Peroxisome Biogenesis Is a Metabolic Strategy for Herpesvirus Replication. Cell host \& microbe 24, 526-541.e7 (2018).

21. Choi, Y. B., Choi, Y. \& Harhaj, E. W. Peroxisomes support human herpesvirus 8 latency by stabilizing the viral oncogenic protein VFLIP via the MAVS-TRAF complex. PLoS pathogens 14, e1007058 (2018).

22. Magalhães, A. C. et al. Peroxisomes are platforms for cytomegalovirus' evasion from the cellular immune response. Scientific reports 6, 26028 (2016).

23. Zheng, C. \& Su, C. Herpes simplex virus 1 infection dampens the immediate early antiviral innate immunity signaling from peroxisomes by tegument protein VP16. Virology journal 14, 35 (2017).

24. Barton, E., Mandal, P. \& Speck, S. H. Pathogenesis and host control of gammaherpesviruses: lessons from the mouse. Annual review of immunology 29, 351-397 (2011).

25. Reese, T. et al. Helminth infection reactivates latent $y$-herpesvirus via cytokine competition at a viral promoter. Science 345, 573-577 (2014).

26. Reese, T. A. Co-infections: Another Variable in the Herpesvirus Latency-Reactivation Dynamic. Journal of virology 90, JVI.01865-15-5537 (2016).

27. Reddy, J. \& Hashimoto, T. Peroxisomal beta-oxidation and peroxisome proliferator-activated receptor alpha: an adaptive metabolic system. Annual review of nutrition 21, 193-230 (2001).

28. Teissier, E. et al. Peroxisome proliferator-activated receptor alpha induces NADPH oxidase activity in macrophages, leading to the generation of LDL with PPAR-alpha activation properties. Circulation research 95, 1174-82 (2004).

29. Nguyen, T., Nioi, P. \& Pickett, C. B. The Nrf2-antioxidant response element signaling pathway and its activation by oxidative stress. The Journal of biological chemistry 284, 13291-5 (2009). 
30. Chan, K., Lu, R., Chang, J. \& Kan, Y. NRF2, a member of the NFE2 family of transcription factors, is not essential for murine erythropoiesis, growth, and development. Proceedings of the National Academy of Sciences of the United States of America 93, 13943-8 (1996).

31. Itoh, K. et al. An Nrf2/small Maf heterodimer mediates the induction of phase II detoxifying enzyme genes through antioxidant response elements. Biochemical and biophysical research communications 236, 313-22 (1997).

32. McMahon, M. et al. The Cap'n'Collar basic leucine zipper transcription factor Nrf2 (NF-E2 p45-related factor 2) controls both constitutive and inducible expression of intestinal detoxification and glutathione biosynthetic enzymes. Cancer research 61, 3299-307 (2001).

33. Dutia, B., Allen, D., Dyson, H. \& Nash, A. Type I interferons and IRF-1 play a critical role in the control of a gammaherpesvirus infection. Virology 261, 173-179

34. Hwang, S. et al. Persistent gammaherpesvirus replication and dynamic interaction with the host in vivo. Journal of virology 82, 12498-12509 (2008).

35. den Bossche, J., O’Neill, L. A. \& Menon, D. Macrophage Immunometabolism: Where Are We (Going)? Trends in immunology 38, 395-406 (2017).

36. Hall, C. J. et al. Immunoresponsive gene 1 augments bactericidal activity of macrophagelineage cells by regulating $\beta$-oxidation-dependent mitochondrial ROS production. Cell metabolism 18, 265-78 (2013).

37. Moon, J.-S. S. et al. NOX4-dependent fatty acid oxidation promotes NLRP3 inflammasome activation in macrophages. Nature medicine 22, 1002-12 (2016).

38. Bulua, A. C. et al. Mitochondrial reactive oxygen species promote production of proinflammatory cytokines and are elevated in TNFR1-associated periodic syndrome (TRAPS). The Journal of experimental medicine 208, 519-33 (2011).

39. Dixit, E. et al. Peroxisomes are signaling platforms for antiviral innate immunity. Cell 141, 668-81 (2010).

40. Odendall, C. et al. Diverse intracellular pathogens activate type III interferon expression from peroxisomes. Nature immunology 15, 717-26 (2014).

41. Shang, G., Zhang, C., Chen, Z. J., Bai, X.-C. C. \& Zhang, X. Cryo-EM structures of STING reveal its mechanism of activation by cyclic GMP-AMP. Nature 567, 389-393 (2019).

42. Ergun, S. L., Fernandez, D., Weiss, T. M. \& Li, L. STING Polymer Structure Reveals Mechanisms for Activation, Hyperactivation, and Inhibition. Cell 178, 290-301.e10 (2019).

43. Jin, L., Lenz, L. L. \& Cambier, J. C. Cellular reactive oxygen species inhibit MPYS induction of IFNß. PloS one 5, e15142 (2010). 
A

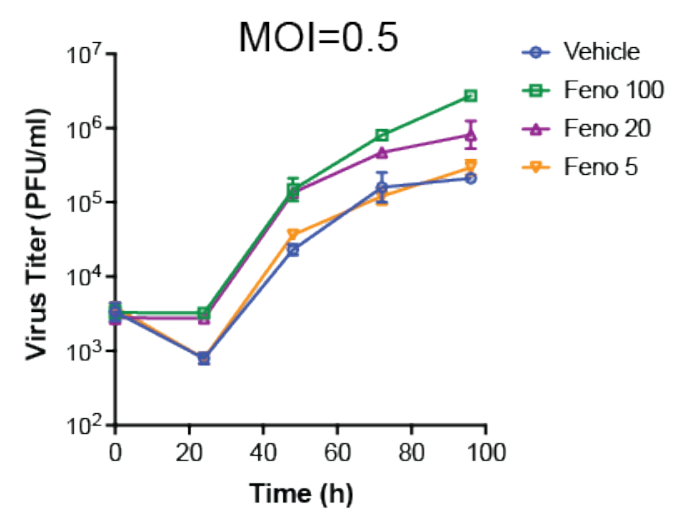

$\mathrm{B}$

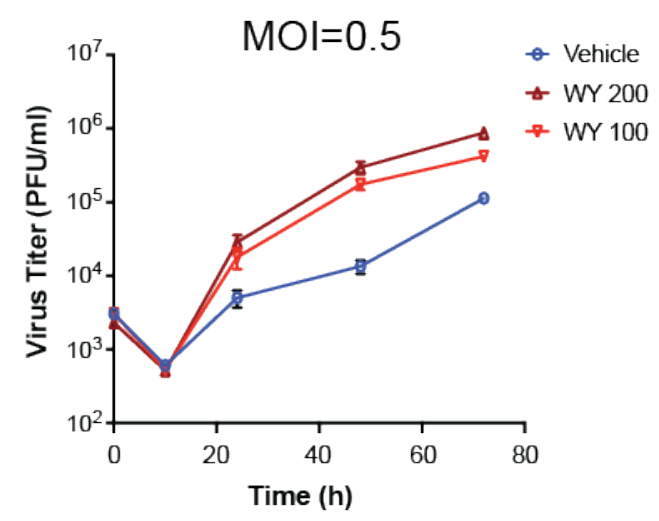

\section{Supplemental Figure 1. Viral replication with different doses of fenofibrate and} WY14643.

(A) Macrophages from C57BL6/J mice were treated with vehicle or increasing doses of fenofibrate $(5,20$, or $100 \mu \mathrm{M})$ for 16 hours. Cells were infected with MHV6 8 at MOI=0.5 and viral growth was quantitated by plaque assay on $3 T 12$ cells.

(B) Macrophages from C57BL6/J mice were treated with vehicle or increasing doses of WY14643 (100 or $200 \mu \mathrm{M})$ for 16 hours. Cells were infected with MHV68 at MOI=0.5 and viral growth was quantitated by plaque assay on $3 T 12$ cells. 


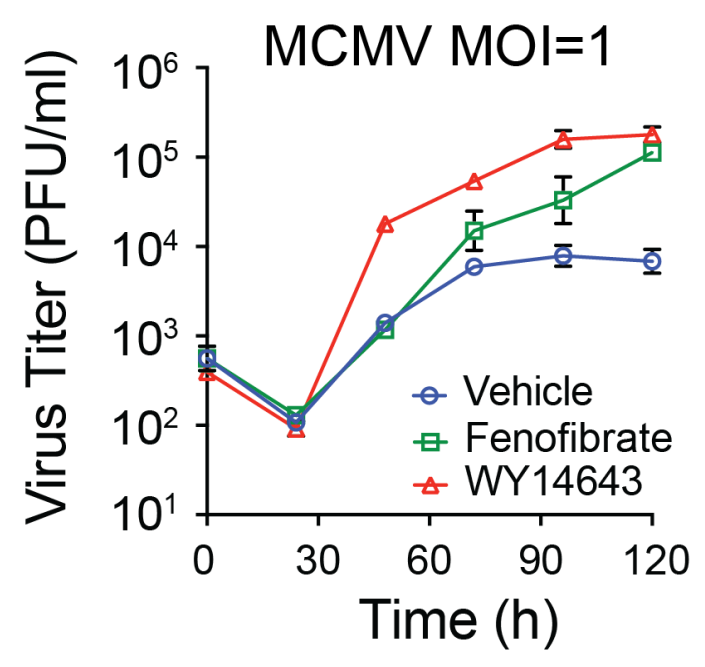

Supplemental Figure 2. PPAR- $\alpha$ stimulation increases virus replication of MCMV. Growth curve of MCMV in macrophages isolated from C57BL/6J mice after pretreatment with vehicle, WY14643 or fenofibrate. Cells were infected with MCMV at $\mathrm{MOI}=1$. Data represents mean $\pm \mathrm{SD}$ from 2 independent experiments. 

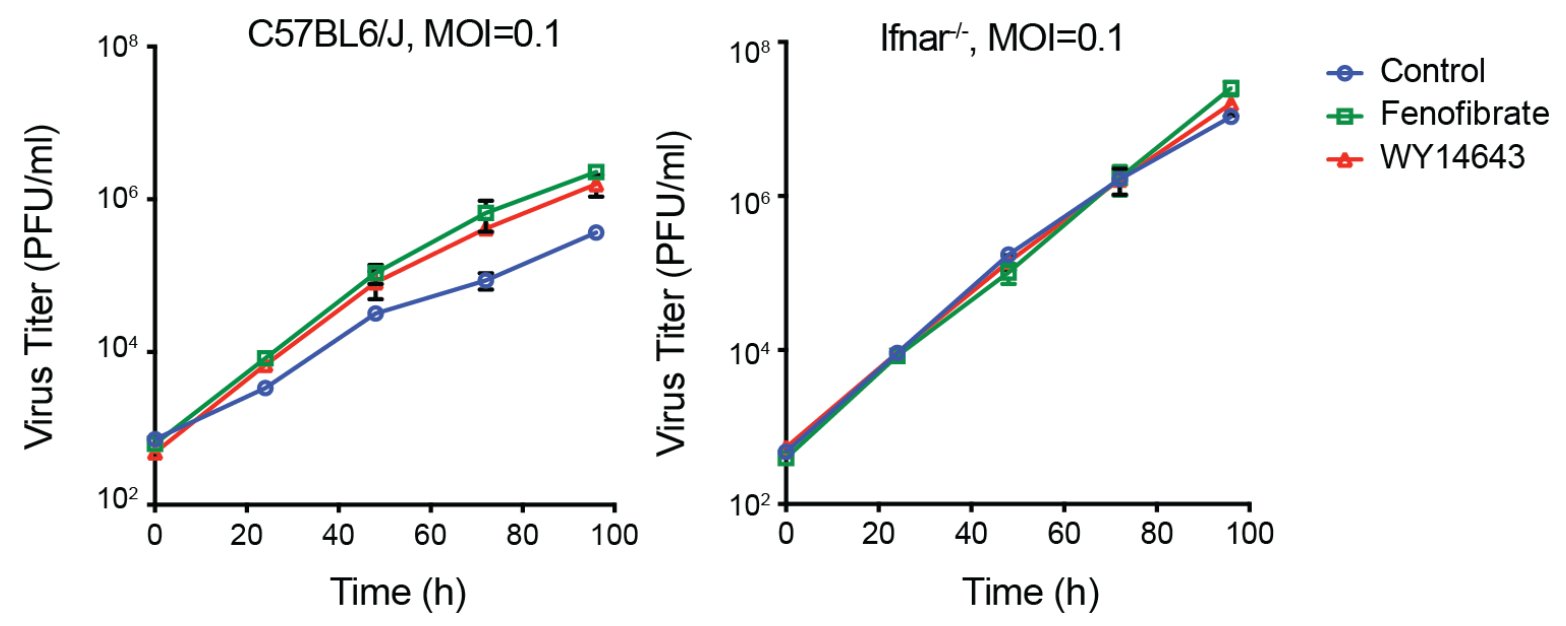

Supplemental Figure 3. Effects of PPAR- $\alpha$ stimulation are IFNAR-dependent.

Macrophages from C57BL6/J mice or Ifnar/- mice were treated with vehicle, fenofibrate or WY14643 for 16 hours. Cells were infected with MHV68 at MOI=0.1 and viral growth was quantitated by plaque assay on $3 T 12$ cells. 


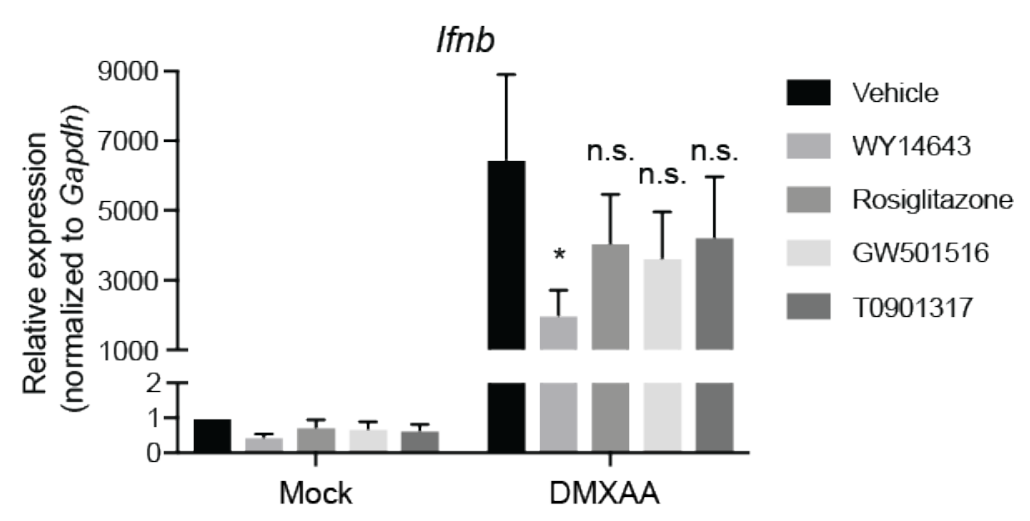

Supplemental Figure 4. Ifnb expression after treatment with PPAR- $\alpha$, PPAR- $\gamma$,

PPAR- $\delta$, or LXR- $\alpha$ agonists. Macrophages from C57BL6/J mice were treated with vehicle, WY14643, rosiglitazone, GW501516, or T0901319 for 16 hours. Cells were then transfected with DMXAA and Ifnb expression was quantitated from lysates 2 hours after transfection. Expression was normalized to Gapdh. Data all shown as mean \pm SD; ${ }^{*} p<0.05$, n.s. (not significant), relative to DMXAA/vehicle treated. Statistical analysis was conducted using two-way ANOVA test. 
Table 1. Differential expression of genes involved in innate inflammatory response

\begin{tabular}{|c|c|c|c|c|c|c|c|c|c|c|c|c|c|c|c|c|c|c|}
\hline \multirow{2}{*}{ Gene } & \multicolumn{3}{|c|}{ Mock } & \multicolumn{3}{|c|}{ WY14643 } & \multicolumn{3}{|c|}{ MHV68 } & \multicolumn{3}{|c|}{ MHV68+WY14643 } & \multirow{2}{*}{ cGAS } & \multirow{2}{*}{ PRR } & \multirow{2}{*}{$\begin{array}{c}\text { NF-kB } \\
\text { Signaling }\end{array}$} & \multirow{2}{*}{$\begin{array}{c}\text { IL-6 } \\
\text { Signaling }\end{array}$} & \multirow{2}{*}{$\begin{array}{l}\text { Interferon } \\
\text { Signaling }\end{array}$} & \multirow{2}{*}{$\begin{array}{c}\text { Acute } \\
\text { Phase } \\
\text { Response } \\
\text { Signaling }\end{array}$} \\
\hline & 1 & 2 & 3 & 1 & 2 & 3 & 1 & 2 & 3 & 1 & 2 & 3 & & & & & & \\
\hline IL18 & 214 & 181 & 177 & 166 & 184 & 187 & 2342 & 2438 & 1992 & 1720 & 1678 & 1694 & & $\sqrt{ }$ & $\sqrt{ }$ & $\sqrt{ }$ & & $\sqrt{ }$ \\
\hline TNF & 1498 & 1498 & 2067 & 906 & 880 & 922 & 7828 & 7552 & 9224 & 2083 & 2178 & 2160 & & $\sqrt{ }$ & $\checkmark$ & $\sqrt{ }$ & & $\sqrt{ }$ \\
\hline NFKBIE & 1115 & 1114 & 1425 & 710 & 718 & 658 & 4615 & 4386 & 4872 & 1432 & 1454 & 1466 & & $\sqrt{ }$ & $\sqrt{ }$ & $\sqrt{ }$ & & $\sqrt{ }$ \\
\hline IL1RN & 1340 & 1545 & 1464 & 547 & 527 & 514 & 5950 & 5147 & 5320 & 1755 & 1690 & 1957 & & $\sqrt{ }$ & $\sqrt{ }$ & $\sqrt{ }$ & & $\sqrt{ }$ \\
\hline IL1A & 2 & 5 & 4 & 2 & 1 & 4 & 11 & 12 & 7 & 7 & 5 & 6 & & $\checkmark$ & $\sqrt{ }$ & $\sqrt{ }$ & & $\sqrt{ }$ \\
\hline NFKBIB & 1048 & 993 & 1001 & 701 & 639 & 693 & 2365 & 2360 & 2255 & 1204 & 1170 & 1239 & & $\sqrt{ }$ & $\sqrt{ }$ & $\sqrt{ }$ & & $\sqrt{ }$ \\
\hline NFKBID & 467 & 454 & 580 & 579 & 581 & 587 & 1015 & 987 & 1250 & 638 & 761 & 644 & & $\sqrt{ }$ & $\sqrt{ }$ & $\sqrt{ }$ & & $\sqrt{ }$ \\
\hline TRAF2 & 645 & 642 & 665 & 534 & 543 & 561 & 1418 & 1407 & 1315 & 723 & 682 & 758 & & $\sqrt{ }$ & $\checkmark$ & $\sqrt{ }$ & & $\sqrt{ }$ \\
\hline FGFR1 & 26 & 33 & 16 & 51 & 45 & 49 & 57 & 46 & 71 & 133 & 111 & 130 & & $\checkmark$ & $\sqrt{ }$ & $\sqrt{ }$ & & \\
\hline PIK3R6 & 428 & 466 & 500 & 472 & 503 & 433 & 993 & 880 & 1068 & 690 & 669 & 631 & & $\sqrt{ }$ & $\sqrt{ }$ & $\checkmark$ & & \\
\hline MYD88 & 2254 & 2195 & 2088 & 1965 & 2059 & 2004 & 9418 & 9895 & 9174 & 5842 & 5502 & 5838 & & $\sqrt{ }$ & $\sqrt{ }$ & & & $\sqrt{ }$ \\
\hline TLR3 & 421 & 427 & 444 & 378 & 340 & 355 & 10029 & 8707 & 11218 & 5054 & 5306 & 5146 & & $\sqrt{ }$ & $\sqrt{ }$ & & & \\
\hline EIF2AK2 & 1538 & 1482 & 1706 & 1108 & 1144 & 1171 & 12635 & 11494 & 14915 & 10992 & 10945 & 10909 & & $\sqrt{ }$ & $\checkmark$ & & & \\
\hline TLR2 & 10294 & 9509 & 11192 & 4098 & 4381 & 4192 & 32293 & 32202 & 32585 & 10216 & 9579 & 10529 & & $\sqrt{ }$ & $\sqrt{ }$ & & & \\
\hline CASP8 & 2315 & 2384 & 2334 & 2862 & 2842 & 2834 & 6680 & 6252 & 6824 & 5428 & 5339 & 5493 & & $\sqrt{ }$ & $\sqrt{ }$ & & & \\
\hline TNFSF13B & 38 & 31 & 33 & 15 & 24 & 21 & 126 & 72 & 71 & 46 & 43 & 47 & & $\sqrt{ }$ & $\sqrt{ }$ & & & \\
\hline TLR7 & 5389 & 5467 & 5714 & 3498 & 3413 & 3314 & 14199 & 12773 & 16330 & 9071 & 9016 & 9201 & & $\sqrt{ }$ & $\sqrt{ }$ & & & \\
\hline TLR9 & 531 & 562 & 595 & 428 & 462 & 391 & 1478 & 962 & 1968 & 698 & 677 & 666 & & $\sqrt{ }$ & $\checkmark$ & & & \\
\hline TANK & 1682 & 1676 & 1782 & 1158 & 1102 & 1181 & 4226 & 4062 & 4476 & 1977 & 1885 & 1965 & & $\sqrt{ }$ & $\sqrt{ }$ & & & \\
\hline TLR8 & 3210 & 3237 & 3607 & 4598 & 4490 & 4216 & 7612 & 6779 & 9623 & 9866 & 9657 & 9574 & & $\checkmark$ & $\checkmark$ & & & \\
\hline TLR6 & 469 & 466 & 455 & 461 & 421 & 416 & 974 & 867 & 987 & 703 & 601 & 687 & & $\sqrt{ }$ & $\sqrt{ }$ & & & \\
\hline IL6 & 0 & 1 & 0 & 0 & 0 & 0 & 17 & 19 & 12 & 0 & 0 & 1 & & $\sqrt{ }$ & & $\sqrt{ }$ & & $\checkmark$ \\
\hline IKBKE & 2727 & 2630 & 3106 & 2355 & 2312 & 2210 & 5996 & 5642 & 6981 & 3036 & 3082 & 3026 & & $\sqrt{ }$ & & $\sqrt{ }$ & & $\sqrt{ }$ \\
\hline RASD2 & 6 & 6 & 5 & 6 & 4 & 3 & 10 & 10 & 16 & 6 & 6 & 10 & & $\sqrt{ }$ & & $\checkmark$ & & $\checkmark$ \\
\hline IFNB1 & 1 & 1 & 0 & 0 & 0 & 0 & 44 & 34 & 35 & 1 & 0 & 5 & & $\sqrt{ }$ & & & $\sqrt{ }$ & \\
\hline OAS3 & 1140 & 1141 & 1375 & 423 & 432 & 472 & 20896 & 17992 & 24239 & 17435 & 18349 & 17669 & & $\sqrt{ }$ & & & $\sqrt{ }$ & \\
\hline OAS1G & 189 & 233 & 200 & 82 & 89 & 104 & 3479 & 3341 & 3363 & 2206 & 2189 & 2223 & & $\sqrt{ }$ & & & $\sqrt{ }$ & \\
\hline OAS1B & 67 & 76 & 85 & 62 & 58 & 57 & 991 & 970 & 1181 & 640 & 774 & 728 & & $\checkmark$ & & & $\checkmark$ & \\
\hline OAS1A & 1021 & 1027 & 1007 & 453 & 448 & 473 & 11361 & 11963 & 10270 & 8194 & 7779 & 8206 & & $\checkmark$ & & & $\checkmark$ & \\
\hline
\end{tabular}




\begin{tabular}{|c|c|c|c|c|c|c|c|c|c|c|c|c|c|c|c|c|c|c|}
\hline \multirow{2}{*}{ Gene } & \multicolumn{3}{|c|}{ Mock } & \multicolumn{3}{|c|}{ WY14643 } & \multicolumn{3}{|c|}{ MHV68 } & \multicolumn{3}{|c|}{ MHV68+WY14643 } & \multirow[t]{2}{*}{ cGAS } & \multirow[t]{2}{*}{ PRR } & \multirow{2}{*}{$\begin{array}{c}\text { NF-kB } \\
\text { Signaling }\end{array}$} & \multirow{2}{*}{$\begin{array}{c}\text { IL-6 } \\
\text { Signaling }\end{array}$} & \multirow{2}{*}{$\begin{array}{l}\text { Interferon } \\
\text { Signaling }\end{array}$} & \multirow{2}{*}{$\begin{array}{c}\text { Acute } \\
\text { Phase } \\
\text { Response } \\
\text { Signaling }\end{array}$} \\
\hline & 1 & 2 & 3 & 1 & 2 & 3 & 1 & 2 & 3 & 1 & 2 & 3 & & & & & & \\
\hline OAS1C & 117 & 111 & 92 & 86 & 77 & 74 & 798 & 912 & 774 & 578 & 581 & 601 & & $\sqrt{ }$ & & & $\sqrt{ }$ & \\
\hline OAS2 & 756 & 766 & 1041 & 554 & 522 & 606 & 6160 & 4675 & 8929 & 5527 & 7345 & 5504 & & $\checkmark$ & & & $\sqrt{ }$ & \\
\hline C3 & 1174 & 1109 & 1159 & 479 & 499 & 448 & 13193 & 11612 & 15130 & 3365 & 3258 & 3503 & & $\checkmark$ & & & & $\checkmark$ \\
\hline TNFSF10 & 57 & 38 & 77 & 6 & 7 & 3 & 8736 & 8454 & 9395 & 3696 & 3442 & 3747 & & $\sqrt{ }$ & & & & \\
\hline CCL5 & 81 & 72 & 49 & 16 & 18 & 10 & 4182 & 4011 & 3520 & 437 & 368 & 437 & & $\sqrt{ }$ & & & & \\
\hline IRF7 & 772 & 815 & 783 & 150 & 173 & 159 & 41147 & 40260 & 40824 & 26639 & 26479 & 27343 & & $\sqrt{ }$ & & & & \\
\hline IFIH1 & 779 & 753 & 843 & 440 & 492 & 461 & 19733 & 19001 & 21380 & 11666 & 11350 & 11898 & & $\sqrt{ }$ & & & & \\
\hline TNFSF4 & 18 & 13 & 11 & 31 & 41 & 34 & 336 & 235 & 296 & 206 & 173 & 209 & & $\checkmark$ & & & & \\
\hline DDX58 & 1163 & 1235 & 1444 & 624 & 600 & 595 & 22888 & 21147 & 26983 & 18054 & 18158 & 17569 & & $\sqrt{ }$ & & & & \\
\hline TNFSF15 & 11 & 14 & 7 & 3 & 3 & 4 & 181 & 180 & 208 & 39 & 38 & 37 & & $\sqrt{ }$ & & & & \\
\hline DHX58 & 914 & 946 & 913 & 474 & 423 & 431 & 14302 & 14384 & 14283 & 10439 & 10498 & 10630 & & $\sqrt{ }$ & & & & \\
\hline IL15 & 383 & 365 & 330 & 343 & 318 & 303 & 4611 & 5055 & 4337 & 2110 & 1883 & 2100 & & $\sqrt{ }$ & & & & \\
\hline TNFSF8 & 105 & 100 & 104 & 27 & 35 & 41 & 1236 & 1072 & 1240 & 442 & 470 & 499 & & $\sqrt{ }$ & & & & \\
\hline NOD1 & 270 & 264 & 288 & 308 & 303 & 294 & 2845 & 2959 & 3223 & 1535 & 1358 & 1616 & & $\checkmark$ & & & & \\
\hline PRKCE & 11 & 15 & 19 & 19 & 21 & 22 & 133 & 96 & 155 & 100 & 86 & 99 & & $\sqrt{ }$ & & & & \\
\hline TRAF1 & 150 & 168 & 186 & 71 & 73 & 77 & 1306 & 1071 & 1148 & 199 & 181 & 216 & & $\sqrt{ }$ & & & & \\
\hline NOD2 & 186 & 207 & 205 & 175 & 137 & 139 & 1270 & 1130 & 1498 & 584 & 502 & 521 & & $\sqrt{ }$ & & & & \\
\hline IL10 & 37 & 38 & 30 & 26 & 24 & 21 & 172 & 198 & 185 & 63 & 58 & 78 & & $\sqrt{ }$ & & & & \\
\hline CASP1 & 2087 & 2038 & 2095 & 1881 & 1871 & 1987 & 10078 & 10059 & 9223 & 6595 & 6505 & 6608 & & $\checkmark$ & & & & \\
\hline RIPK2 & 488 & 508 & 503 & 397 & 450 & 428 & 1906 & 1971 & 2007 & 1025 & 868 & 990 & & $\sqrt{ }$ & & & & \\
\hline TRIM25 & 2609 & 2607 & 2681 & 3196 & 3243 & 3160 & 8390 & 7793 & 9505 & 7358 & 7478 & 7335 & & $\sqrt{ }$ & & & & \\
\hline IRAK2 & 1569 & 1516 & 1703 & 1172 & 1144 & 1118 & 4749 & 4796 & 4977 & 2506 & 2407 & 2619 & & $\sqrt{ }$ & & & & \\
\hline LTB & 6 & 3 & 10 & 7 & 8 & 9 & 13 & 16 & 18 & 13 & 9 & 11 & & $\sqrt{ }$ & & & & \\
\hline UBC & 1912 & 1952 & 2446 & 2259 & 2271 & 2144 & 5354 & 5568 & 4599 & 4788 & 4751 & 4965 & & $\sqrt{ }$ & & & & \\
\hline RELB & 1280 & 1279 & 1423 & 643 & 676 & 648 & 2960 & 2877 & 3028 & 1235 & 1319 & 1394 & & $\sqrt{ }$ & & & & \\
\hline АKT3 & 1145 & 1188 & 1307 & 1350 & 1403 & 1392 & 4945 & 4111 & 5354 & 3544 & 3477 & 3528 & & & $\sqrt{ }$ & $\sqrt{ }$ & & $\sqrt{ }$ \\
\hline TNFRSF1B & 11046 & 10749 & 11198 & 11923 & 12072 & 11725 & 26748 & 24892 & 26938 & 21453 & 20583 & 22081 & & & $\checkmark$ & $\sqrt{ }$ & & $\sqrt{ }$ \\
\hline RAF1 & 2717 & 2725 & 2818 & 2829 & 2810 & 2989 & 5410 & 5632 & 5480 & 3984 & 3973 & 3967 & & & $\sqrt{ }$ & $\sqrt{ }$ & & $\checkmark$ \\
\hline IL1R2 & 16 & 20 & 17 & 6 & 8 & 11 & 46 & 64 & 48 & 48 & 24 & 44 & & & $\checkmark$ & $\sqrt{ }$ & & \\
\hline STAT3 & 2636 & 2581 & 2720 & 2997 & 3128 & 3133 & 6711 & 6102 & 7306 & 5448 & 5229 & 5591 & & & $\sqrt{ }$ & & & $\checkmark$ \\
\hline FLT4 & 6 & 6 & 5 & 7 & 5 & 5 & 298 & 219 & 257 & 141 & 155 & 168 & & & $\sqrt{ }$ & & & \\
\hline
\end{tabular}




\begin{tabular}{|c|c|c|c|c|c|c|c|c|c|c|c|c|c|c|c|c|c|c|}
\hline \multirow{2}{*}{ Gene } & \multicolumn{3}{|c|}{ Mock } & \multicolumn{3}{|c|}{ WY14643 } & \multicolumn{3}{|c|}{ MHV68 } & \multicolumn{3}{|c|}{ MHV68+WY14643 } & \multirow[t]{2}{*}{ cGAS } & \multirow[t]{2}{*}{ PRR } & \multirow{2}{*}{$\begin{array}{c}\text { NF-kB } \\
\text { Signaling }\end{array}$} & \multirow{2}{*}{$\begin{array}{c}\text { IL-6 } \\
\text { Signaling }\end{array}$} & \multirow{2}{*}{$\begin{array}{l}\text { Interferon } \\
\text { Signaling }\end{array}$} & \multirow{2}{*}{$\begin{array}{c}\text { Acute } \\
\text { Phase } \\
\text { Response } \\
\text { Signaling }\end{array}$} \\
\hline & 1 & 2 & 3 & 1 & 2 & 3 & 1 & 2 & 3 & 1 & 2 & 3 & & & & & & \\
\hline CD40 & 241 & 224 & 225 & 52 & 66 & 58 & 8145 & 8503 & 7354 & 2111 & 2001 & 2282 & & & $\sqrt{ }$ & & & \\
\hline KDR & 459 & 502 & 491 & 158 & 190 & 167 & 6428 & 5838 & 7733 & 2610 & 2305 & 2611 & & & $\sqrt{ }$ & & & \\
\hline LCK & 3 & 8 & 8 & 7 & 5 & 10 & 71 & 69 & 63 & 50 & 34 & 41 & & & $\sqrt{ }$ & & & \\
\hline FLT1 & 180 & 190 & 199 & 146 & 128 & 136 & 1388 & 1091 & 1428 & 737 & 675 & 603 & & & $\sqrt{ }$ & & & \\
\hline $\mathrm{AZI2}$ & 1206 & 1171 & 1153 & 1122 & 1104 & 1165 & 5505 & 5316 & 5657 & 4208 & 4033 & 4081 & & & $\sqrt{ }$ & & & \\
\hline PELI1 & 1274 & 1231 & 1252 & 1057 & 1012 & 1060 & 5312 & 5420 & 5837 & 2669 & 2403 & 2658 & & & $\sqrt{ }$ & & & \\
\hline BMP2 & 24 & 23 & 21 & 5 & 5 & 7 & 70 & 76 & 109 & 22 & 8 & 16 & & & $\sqrt{ }$ & & & \\
\hline TNFAIP3 & 1394 & 1344 & 1533 & 743 & 713 & 674 & 4082 & 3777 & 4771 & 1402 & 1368 & 1419 & & & $\sqrt{ }$ & & & \\
\hline MAP3K8 & 248 & 238 & 255 & 321 & 312 & 290 & 615 & 625 & 660 & 430 & 407 & 464 & & & $\sqrt{ }$ & & & \\
\hline HDAC1 & 1141 & 1145 & 1196 & 1066 & 1040 & 1061 & 2699 & 2781 & 2588 & 1917 & 1923 & 1980 & & & $\sqrt{ }$ & & & \\
\hline socs1 & 28 & 33 & 30 & 23 & 20 & 14 & 953 & 1044 & 901 & 287 & 235 & 264 & & & & $\sqrt{ }$ & $\sqrt{ }$ & $\sqrt{ }$ \\
\hline JAK2 & 919 & 925 & 1001 & 904 & 962 & 953 & 7304 & 6852 & 7891 & 4262 & 4168 & 4193 & & & & $\sqrt{ }$ & $\sqrt{ }$ & $\sqrt{ }$ \\
\hline socs3 & 161 & 147 & 181 & 75 & 87 & 72 & 768 & 793 & 919 & 165 & 180 & 159 & & & & $\sqrt{ }$ & $\sqrt{ }$ & \\
\hline CEBPB & 1690 & 1677 & 1865 & 1568 & 1350 & 1260 & 5033 & 5023 & 5532 & 3049 & 3278 & 3081 & & & & $\sqrt{ }$ & & $\checkmark$ \\
\hline IL1RAP & 243 & 249 & 254 & 275 & 260 & 287 & 762 & 704 & 721 & 708 & 756 & 757 & & & & $\sqrt{ }$ & & $\sqrt{ }$ \\
\hline MAP2K1 & 4735 & 4703 & 4591 & 4638 & 4544 & 4542 & 11578 & 11466 & 11049 & 10140 & 9435 & 9856 & & & & $\sqrt{ }$ & & $\sqrt{ }$ \\
\hline TNFAIP6 & 0 & 1 & 0 & 1 & 1 & 1 & 20 & 18 & 5 & 6 & 2 & 8 & & & & $\sqrt{ }$ & & \\
\hline MCL1 & 13370 & 13145 & 14265 & 10744 & 10256 & 10032 & 36309 & 36405 & 37898 & 21989 & 22645 & 22945 & & & & $\sqrt{ }$ & & \\
\hline MAPKAPK2 & 7602 & 7229 & 7788 & 5230 & 5062 & 5124 & 19231 & 19768 & 19006 & 9309 & 9084 & 9768 & & & & $\sqrt{ }$ & & \\
\hline IL18RAP & 93 & 98 & 81 & 127 & 129 & 132 & 183 & 173 & 200 & 114 & 92 & 111 & & & & $\checkmark$ & & \\
\hline IFIT3 & 699 & 752 & 718 & 68 & 83 & 84 & 71547 & 76452 & 75258 & 52105 & 48862 & 51428 & & & & & $\sqrt{ }$ & \\
\hline ISG15 & 467 & 442 & 412 & 69 & 63 & 68 & 32503 & 34593 & 29861 & 18088 & 17179 & 18568 & & & & & $\sqrt{ }$ & \\
\hline STAT1 & 4405 & 4219 & 4528 & 2076 & 2201 & 2115 & 58462 & 59483 & 63427 & 49801 & 48886 & 49545 & & & & & $\sqrt{ }$ & \\
\hline TAP1 & 1796 & 1669 & 1594 & 1130 & 1211 & 1121 & 19657 & 20391 & 19816 & 13324 & 12700 & 13429 & & & & & $\sqrt{ }$ & \\
\hline IFI35 & 864 & 872 & 808 & 516 & 589 & 578 & 9556 & 10614 & 8826 & 6491 & 6282 & 6391 & & & & & $\sqrt{ }$ & \\
\hline STAT2 & 2294 & 2150 & 2473 & 2140 & 2086 & 2029 & 23292 & 21943 & 27767 & 21528 & 22535 & 21756 & & & & & $\sqrt{ }$ & \\
\hline IRF1 & 1456 & 1280 & 1410 & 877 & 902 & 870 & 9931 & 10321 & 11085 & 3871 & 3612 & 4169 & & & & & $\sqrt{ }$ & \\
\hline PSMB8 & 2270 & 2208 & 2023 & 1597 & 1730 & 1617 & 12367 & 13142 & 11161 & 8068 & 7882 & 8075 & & & & & $\sqrt{ }$ & \\
\hline IFITM3 & 6415 & 6793 & 6129 & 2309 & 2653 & 2393 & 28056 & 28253 & 24744 & 17039 & 16637 & 17767 & & & & & $\checkmark$ & \\
\hline socs7 & 549 & 559 & 534 & 639 & 607 & 542 & 1951 & 1755 & 2336 & 998 & 969 & 1025 & & & & & $\sqrt{ }$ & \\
\hline
\end{tabular}




\begin{tabular}{|c|c|c|c|c|c|c|c|c|c|c|c|c|c|c|c|c|c|c|}
\hline \multirow{2}{*}{ Gene } & \multicolumn{3}{|c|}{ Mock } & \multicolumn{3}{|c|}{ WY14643 } & \multicolumn{3}{|c|}{ MHV68 } & \multicolumn{3}{|c|}{ MHV68+WY14643 } & \multirow[t]{2}{*}{ cGAS } & \multirow[t]{2}{*}{ PRR } & \multirow{2}{*}{$\begin{array}{c}\text { NF-kB } \\
\text { Signaling }\end{array}$} & \multirow{2}{*}{$\begin{array}{c}\text { IL-6 } \\
\text { Signaling }\end{array}$} & \multirow{2}{*}{$\begin{array}{l}\text { Interferon } \\
\text { Signaling }\end{array}$} & \multirow{2}{*}{$\begin{array}{c}\text { Acute } \\
\text { Phase } \\
\text { Response } \\
\text { Signaling }\end{array}$} \\
\hline & 1 & 2 & 3 & 1 & 2 & 3 & 1 & 2 & 3 & 1 & 2 & 3 & & & & & & \\
\hline IRF9 & 1419 & 1387 & 1584 & 1027 & 977 & 1001 & 3698 & 3583 & 3662 & 3237 & 3324 & 3305 & & & & & $\sqrt{ }$ & \\
\hline TYK2 & 2458 & 2323 & 2598 & 2846 & 2750 & 2779 & 5953 & 4969 & 6582 & 4094 & 4265 & 4089 & & & & & $\sqrt{ }$ & \\
\hline CFB & 49 & 57 & 51 & 30 & 35 & 43 & 1543 & 1481 & 1338 & 365 & 396 & 389 & & & & & & $\sqrt{ }$ \\
\hline socs2 & 6 & 7 & 19 & 9 & 9 & 9 & 128 & 121 & 127 & 35 & 27 & 45 & & & & & & $\sqrt{ }$ \\
\hline $\mathrm{CP}$ & 68 & 62 & 72 & 30 & 30 & 20 & 458 & 372 & 441 & 70 & 82 & 70 & & & & & & $\sqrt{ }$ \\
\hline C2 & 6 & 7 & 5 & 3 & 9 & 7 & 40 & 31 & 33 & 18 & 34 & 23 & & & & & & $\sqrt{ }$ \\
\hline C1RA & 59 & 64 & 44 & 32 & 32 & 26 & 232 & 191 & 202 & 87 & 98 & 108 & & & & & & $\sqrt{ }$ \\
\hline $\mathrm{HP}$ & 6 & 9 & 9 & 3 & 0 & 2 & 30 & 31 & 22 & 7 & 7 & 3 & & & & & & $\sqrt{ }$ \\
\hline F8 & 10 & 10 & 9 & 9 & 4 & 3 & 28 & 38 & 32 & 15 & 15 & 8 & & & & & & $\sqrt{ }$ \\
\hline TCF4 & 2157 & 2046 & 2139 & 2014 & 1969 & 1919 & 5627 & 5273 & 6623 & 3476 & 3550 & 3464 & & & & & & $\sqrt{ }$ \\
\hline HMOX2 & 2103 & 2139 & 2025 & 1688 & 1745 & 1845 & 5653 & 5928 & 5272 & 4839 & 4635 & 4826 & & & & & & $\sqrt{ }$ \\
\hline APOA2 & 4 & 7 & 3 & 5 & 4 & 1 & 11 & 11 & 8 & 7 & 4 & 5 & & & & & & $\sqrt{ }$ \\
\hline NFKBIA & 3201 & 3134 & 3526 & 2777 & 2672 & 2730 & 9695 & 10176 & 10278 & 4679 & 4668 & 4725 & $\sqrt{ }$ & $\sqrt{ }$ & $\sqrt{ }$ & $\checkmark$ & & $\sqrt{ }$ \\
\hline CASP12 & 3 & 2 & 1 & 0 & 1 & 0 & 41 & 41 & 44 & 16 & 16 & 13 & $\sqrt{ }$ & & & & & \\
\hline CASP4 & 403 & 346 & 464 & 201 & 202 & 221 & 4588 & 4483 & 4288 & 1987 & 1950 & 2141 & $\sqrt{ }$ & & & & & \\
\hline TREX1 & 1147 & 1150 & 1174 & 674 & 642 & 620 & 11338 & 12083 & 10822 & 6742 & 6376 & 7018 & $\sqrt{ }$ & & & & & \\
\hline SQSTM1 & 17196 & 16704 & 18097 & 24329 & 24385 & 23906 & 33074 & 33293 & 32163 & 36959 & 35126 & 37671 & $\sqrt{ }$ & & & & & \\
\hline TBK1 & 2377 & 2384 & 2397 & 2445 & 2400 & 2397 & 4357 & 4293 & 4487 & 3062 & 3230 & 3201 & $\sqrt{ }$ & & & & & \\
\hline CHUK & 1441 & 1529 & 1573 & 1640 & 1608 & 1568 & 2029 & 1945 & 2083 & 1871 & 1823 & 1826 & $\sqrt{ }$ & & & & & \\
\hline MAP1LC3A & 429 & 391 & 455 & 525 & 461 & 523 & 579 & 585 & 491 & 515 & 521 & 499 & $\sqrt{ }$ & & & & & \\
\hline BAX & 3470 & 3327 & 3128 & 3226 & 3204 & 3212 & 4116 & 4459 & 3952 & 3809 & 3902 & 3871 & $\sqrt{ }$ & & & & & \\
\hline RPS6KB1 & 787 & 790 & 857 & 979 & 1006 & 968 & 779 & 752 & 875 & 834 & 863 & 832 & $\sqrt{ }$ & & & & & \\
\hline IRF3 & 1127 & 1158 & 1171 & 1314 & 1318 & 1297 & 1056 & 1150 & 1135 & 1128 & 1193 & 1141 & $\sqrt{ }$ & & & & & \\
\hline ULK1 & 976 & 933 & 1021 & 1419 & 1423 & 1376 & 550 & 451 & 674 & 913 & 881 & 831 & $\sqrt{ }$ & & & & & \\
\hline
\end{tabular}

List of genes and their expression values across three biological replicates for each of the four groups (Vehicle-treated, WY14643-treated, MHV68-infected, and MHV68-infected/WY14643-treated). Membership of genes in various inflammatory pathways as defined by Ingenuity are listed. 
Table 2. Differential expression of genes involved in cellular oxidative stress with WY14643 treatment

\begin{tabular}{|c|c|c|c|c|c|c|c|c|c|c|}
\hline \multirow{2}{*}{ Gene } & \multicolumn{3}{|c|}{ Mock } & \multicolumn{3}{|c|}{ WY14643 } & \multirow{2}{*}{$\begin{array}{c}\text { Redox } \\
\text { Metabolism }\end{array}$} & \multirow{2}{*}{$\begin{array}{c}\text { Iron } \\
\text { Metabolism }\end{array}$} & \multirow{2}{*}{$\begin{array}{c}\text { Nrf2-Mediated } \\
\text { Oxidative Stress }\end{array}$} & \multirow{2}{*}{$\begin{array}{c}\text { Antioxidant action } \\
\text { of vitamin C }\end{array}$} \\
\hline & 1 & 2 & 3 & 4 & 5 & 6 & & & & \\
\hline Txnrd1 & 4828 & 5101 & 4918 & 14630 & 14375 & 15191 & $\sqrt{ }$ & & $\sqrt{ }$ & \\
\hline Cat & 769 & 791 & 692 & 1777 & 1761 & 1810 & $\sqrt{ }$ & & $\sqrt{ }$ & \\
\hline Gsr & 9 & 16 & 11 & 92 & 97 & 96 & $\sqrt{ }$ & & $\sqrt{ }$ & \\
\hline Gsta3 & 2029 & 2066 & 2272 & 4601 & 4581 & 4414 & $\sqrt{ }$ & & $\sqrt{ }$ & \\
\hline Gstm1 & 26 & 27 & 13 & 35 & 46 & 46 & $\sqrt{ }$ & & $\sqrt{ }$ & \\
\hline Gstp1 & 52 & 61 & 63 & 102 & 115 & 94 & $\sqrt{ }$ & & $\sqrt{ }$ & \\
\hline Gstt2 & 1153 & 1030 & 1088 & 2740 & 2838 & 2751 & $\sqrt{ }$ & & $\sqrt{ }$ & \\
\hline Mgst1 & 46 & 61 & 57 & 149 & 173 & 146 & $\sqrt{ }$ & & $\sqrt{ }$ & \\
\hline Nqo1 & 25451 & 25969 & 25176 & 41463 & 42096 & 44113 & $\sqrt{ }$ & & $\sqrt{ }$ & \\
\hline Prdx1 & 2764 & 2846 & 2704 & 4726 & 4787 & 4796 & $\sqrt{ }$ & & $\sqrt{ }$ & \\
\hline Sod1 & 1529 & 1507 & 1545 & 2365 & 2413 & 2522 & $\sqrt{ }$ & & $\sqrt{ }$ & \\
\hline Prdx6 & 171182 & 175383 & 170069 & 318219 & 297781 & 303528 & $\sqrt{ }$ & & & \\
\hline Ftl1 & 395 & 374 & 413 & 845 & 866 & 738 & & $\sqrt{ }$ & $\sqrt{ }$ & \\
\hline Gdf15 & 3463 & 3641 & 3357 & 8580 & 8300 & 8575 & & $\sqrt{ }$ & & \\
\hline Slc11a1 & 1521 & 1513 & 1711 & 2765 & 2739 & 2793 & & $\sqrt{ }$ & & \\
\hline Slc25a37 & 3312 & 3349 & 2766 & 10243 & 10169 & 9856 & & $\sqrt{ }$ & & \\
\hline Slc40a1 & 7171 & 7229 & 7051 & 11446 & 11255 & 11091 & & $\sqrt{ }$ & & \\
\hline Slc48a1 & 23341 & 23271 & 21494 & 55598 & 51879 & 54662 & & $\sqrt{ }$ & & \\
\hline Hmox1 & 1514 & 1553 & 1775 & 3111 & 2875 & 2869 & & & $\sqrt{ }$ & $\sqrt{ }$ \\
\hline Fos & 6 & 11 & 18 & 22 & 20 & 23 & & & $\sqrt{ }$ & \\
\hline Prkcg & 4600 & 4834 & 4718 & 7321 & 7279 & 7459 & & & $\sqrt{ }$ & \\
\hline Abcc1 & 4 & 4 & 5 & 20 & 21 & 20 & & & $\sqrt{ }$ & \\
\hline Aox1 & 27 & 33 & 27 & 113 & 101 & 113 & & & $\sqrt{ }$ & \\
\hline Dnajb13 & 1735 & 1782 & 1732 & 3403 & 3358 & 3463 & & & $\sqrt{ }$ & \\
\hline Gclc & 2141 & 2187 & 2058 & 7881 & 7657 & 8343 & & & $\sqrt{ }$ & \\
\hline Gclm & 1757 & 1677 & 1801 & 2744 & 2639 & 2745 & & & $\sqrt{ }$ & \\
\hline lkbkg & 26 & 25 & 28 & 43 & 46 & 57 & & & & $\sqrt{ }$ \\
\hline Abhd3 & 2762 & 2689 & 2970 & 5391 & 5051 & 5302 & & & & $\sqrt{ }$ \\
\hline
\end{tabular}




\begin{tabular}{|c|c|c|c|c|c|c|c|c|c|c|}
\hline \multirow{2}{*}{ Gene } & \multicolumn{3}{|c|}{ Mock } & \multicolumn{3}{|c|}{ WY14643 } & \multirow{2}{*}{$\begin{array}{c}\text { Redox } \\
\text { Metabolism }\end{array}$} & \multirow{2}{*}{$\begin{array}{c}\text { Iron } \\
\text { Metabolism }\end{array}$} & \multirow{2}{*}{$\begin{array}{c}\text { Nrf2-Mediated } \\
\text { Oxidative Stress }\end{array}$} & \multirow{2}{*}{$\begin{array}{c}\text { Antioxidant action } \\
\text { of vitamin } C\end{array}$} \\
\hline & 1 & 2 & 3 & 4 & 5 & 6 & & & & \\
\hline Csf2ra & 807 & 791 & 741 & 1746 & 1631 & 1595 & & & & $\sqrt{ }$ \\
\hline Pla2g7 & 7 & 6 & 7 & 2 & 3 & 0 & & & & $\sqrt{ }$ \\
\hline Plb1 & 37 & 33 & 44 & 21 & 26 & 21 & & & & $\sqrt{ }$ \\
\hline Pla2g2e & 1498 & 1498 & 2067 & 906 & 880 & 922 & & & & $\sqrt{ }$ \\
\hline Tnf & 270 & 254 & 299 & 185 & 169 & 194 & & & & $\sqrt{ }$ \\
\hline Plcb4 & 1115 & 1114 & 1425 & 710 & 718 & 658 & & & & $\sqrt{ }$ \\
\hline Nfkbie & 2674 & 2553 & 3021 & 1835 & 1808 & 1725 & & & & $\sqrt{ }$ \\
\hline Nfkb2 & 839 & 915 & 987 & 106 & 128 & 149 & & & & $\sqrt{ }$ \\
\hline Rsad2 & 248 & 241 & 250 & 141 & 128 & 122 & & & $\sqrt{ }$ & \\
\hline Maff & 2481 & 2269 & 2687 & 1394 & 1483 & 1347 & & & $\sqrt{ }$ & \\
\hline Herpud1 & 126 & 152 & 112 & 85 & 64 & 69 & & & $\sqrt{ }$ & \\
\hline Acta2 & 6 & 9 & 9 & 3 & 0 & 2 & & $\sqrt{ }$ & $\sqrt{ }$ & \\
\hline $\mathrm{Hp}$ & 68 & 62 & 72 & 30 & 30 & 20 & & $\sqrt{ }$ & & \\
\hline$C p$ & 7 & 9 & 8 & 3 & 4 & 1 & & & & \\
\hline Sod3 & 4828 & 5101 & 4918 & 14630 & 14375 & 15191 & $\sqrt{ }$ & & $\sqrt{ }$ & \\
\hline
\end{tabular}

List of genes and their expression values across three biological replicates for vehicle-treated and WY14643-treated groups. Membership of genes in various oxidative stress pathways as defined by Ingenuity are listed. 


\section{Material and Methods}

\section{Animals}

C57BL/6J, B6;129S4-Ppar $\alpha^{\mathrm{tm} 1 \mathrm{Gonz}} / \mathrm{J}$, C57BL/6J-Tmem1739t/J, B6(Cg)-Tmem173 1 tm1.2Camb/J,

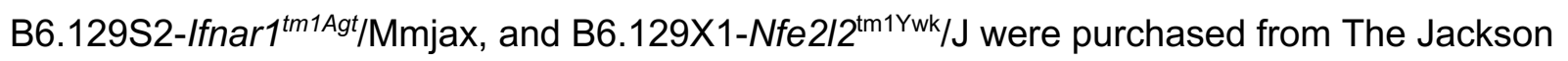
Laboratory. All mice were housed under specific pathogen-free, double-barrier facility at the University of Texas Southwestern Medical Center. Mice were fed autoclaved rodent feed and water. Mice were maintained and used under a protocol approved by UT Southwestern Medical Center Institutional Animal Care and Use Committee (IACUC).

\section{Chemicals}

For in vitro experiments, PPAR $\alpha$ agonists, Fenofibrate and WY14643; PPAR $\beta$ agonist, GW501516; PPAR $\gamma$ agonist, Rosiglitazone were purchased from Sigma. For in vivo experiments, WY14643 was purchased from Cayman. Hydrogen peroxide solution and NAcetyl-L-Cysteine was purchased from Sigma.

\section{Cell culture}

Bone marrow derived macrophages were differentiated in DMEM (Corning) with 10\% FBS supplemented with 1\% glutamine (Corning), 1\% HEPES (Corning) and 10\% CMG14 supernatant for 7 days ${ }^{1}$. 3T12 cells were maintained in DMEM with 5\% FBS supplemented with $1 \%$ glutamine and $1 \%$ HEPES.

\section{Generation of virus stocks}

Murine $\gamma$-herpesvirus 68 (WUSM stain) was purchased from ATCC. Murine $\gamma$-herpesvirus 68M3FL was generated as previously reported ${ }^{2}$.

\section{Virus infection}

Fully differentiated BMDMs were seeded on 24 well plates $\left(1.5 \times 10^{5}\right.$ cells per well) or 6 well plate $\left(10^{6}\right.$ cells per well). Cells were pretreated with either vehicle control ( $0.1 \%$ DMSO) or agonists (Fenofibrate $50 \mu \mathrm{M}$, WY14643 $200 \mu \mathrm{M}$, Rosiglitazone $1 \mu \mathrm{M}$, GW501516 $100 \mathrm{nM}$ ) for 16 hours. The next days, macrophages were infected with MHV68 at multiplicity of infection (MOI) $=5$ or 0.1. For MCMV experiments, cells were infected at $\mathrm{MOI}=1$. After an hour, cells were washed with PBS twice to remove unabsorbed viruses and resuspended in medium containing 
treatments. For growth curve, samples were collected at 0 hour, 24 hours, 48 hours, 72 hours and 96 hours after infection and were frozen at $-80^{\circ} \mathrm{C}$. The titer of virus was determined by plaque assay in 3T12 cells. For flow cytometric analysis, cells were collected 24 hours after infection.

\section{Flow cytometry for MHV68 lytic proteins positive cells}

To determine the percentage of cells that expressing lytic proteins of MHV68 infection, cells were harvested 24 hours after infection, and fixed with $2 \%$ formaldehyde, blocked with $10 \%$ mouse serum and 1\% Fc block (CD16/32, BioLegend), then stained with polyclonal rabbit antibody to MHV68 $(1: 1000)^{3,4}$, followed by secondary goat anti-rabbit Alexa Fluor-647 (Invitrogen).

\section{Transfection}

Cells were seeded on 6 well plates and treated as needed. Cells were transfected with STING ligand (DMXAA, $10 \mu \mathrm{g} / \mathrm{ml}$, InvivoGen) using Lipofectamine 3000 (Thermo Fisher Scientific) according to the manufacturer's protocol.

\section{Plaque assay}

The concentration of virus was titered in 3 T12 cells. The frozen samples containing viruses were thawed in incubator. The samples were serial diluted, then added to a monolayer of 3T12 cells. After an hour of absorption, the cells were then covered with $1 \%$ methylcellulose. Plates were incubated at $37{ }^{\circ} \mathrm{C}$ for 7 days, and the plaques were stained with $0.1 \%$ crystal violet.

\section{Western blot}

Cells were lysed with RIPA buffer (150 mM NaCl, $1 \%$ NP-40, 0.5\% sodium deoxycholate, $0.1 \%$ SDS, $25 \mathrm{mM}$ Tris with protease inhibitor cocktail). Protein concentration were determined using Bradford assay (Bio-Rad). Equal amounts of protein were mixed with $5 \times$ loading sample buffer, resolved by $4-12 \%$ Bis-Tris plus gels (Thermo Fisher Scientific), and transferred to nitrocellulose membrane. Proteins were labeled with primary antibodies against STING (1:1000, Catalogue no.13647S, Cell Signaling), TBK1 (1:1000, Catalogue no. 3504S, Cell Signaling), IRF3 (1:1000, Catalogue no. 4302S, Cell Signaling), pTBK1 (1:1000, Catalogue no. 5483S, Cell Signaling), pIRF3 (1:1000, Catalogue no. 4947S, Cell Signaling), PPAR $\alpha$ (1:1000, Catalogue no. Sc398394, Santa Cruz), SDHA (1:5000, Catalogue no. ab14715, Abcam), $\beta$-actin (1:5000, Catalogue no. A2228, Sigma). Secondary antibodies used are donkey-anti-rabbit (1:5000, 
Catalogue no.711-035-152, Jackson ImmunoResearch Laboratory) and goat-anti-mouse peroxidase (1:5000, Catalogue no.115-035-174 Jackson ImmunoResearch Laboratory). Membranes were developed using Luminata Forte Western HRP substrate (Millipore).

\section{RT-qPCR}

BMDMs in 6 well plates were either infected with MHV68 at MOI=5 for 6 hours or transfected with STING ligand DMXAA at $10 \mu \mathrm{g} / \mathrm{ml}$ for 2 hours. RNA was extracted using Qiagen RNeasy Mini Kit (Qiagen) and reverse transcribed into cDNA using SuperScript VILO cDNA Synthesis Kit (Thermo Fisher Scientific). Relative quantification of target genes was determined using PowerUp SYBR Green Master Mix (Thermo Fisher Scientific) in a QuantStudio 7 Flex real time PCR system. Primers used for amplifying target genes are listed in Table 3.

\section{IFN $\beta$ ELISA Assay}

BMDMs were seeded in 24 well plates. The next day, cells were treated with either vehicle control or WY14643 for 16 hours. Cells were then transfected with $10 \mu \mathrm{g} / \mathrm{ml}$ DMXAA. Supernatant of cells were collected 24 hours after transfection and frozen at $-80{ }^{\circ} \mathrm{C}$. The concentration of IFN $\beta$ in the supernatant was determined with PBL IFN Beta ELISA Kit (PBL Assay Science).

\section{Total ROS measurement}

The total ROS production was determined using ROS-ID Total ROS detection kit (Enzo) according to the manufacture's protocol. Cells were seeded on 24 well plates, and treatment with indicated compounds or DMSO for 6 hours, followed by incubation with oxidative stress detection reagent for 30 mins at $37^{\circ} \mathrm{C}$. The fluorescence of the detection reagent upon oxidation was analyzed by flow cytometry using a FACSCalibur (BD Biosciences).

\section{MHV68 acute replication in mouse}

Experiments were carried out using 8-12 weeks old male mice under the protocol approved by IACUC. Mice were injected intraperitoneally with either vehicle control (15\% HS15 in normal saline) or WY14643 (100 mg/kg) for 1 week starting from 3 days before virus infection. Mice were then infected with MHV68-M3FL at the dose of $10^{6}$ PFU through intraperitoneal route ${ }^{2,4}$. To quantify virus-encoded luciferase expression, mice were weighed and injected with 150 $\mathrm{mg} / \mathrm{kg}$ of D-Luciferin (GOLDBIO) prior to imaging using IVIS Lumina III In Vivo Imaging System 
(PerkinElmer). Total flux (Photons/second) of the abdominal region was determined using Living Image software (PerkinElmer). Survival of the mice were recorded until 20 days after infection.

\section{RNA seq and data analysis}

RNA samples were extracted with RNeasy Mini Kit (Qiagen) and RNA library was prepared using TruSeq Stranded mRNA Sample Preparation Kit (Illumina). Samples were sequenced on NextSeq 500/500 sequencer (Illumina) with SE-85. RNA seq data is normalized and analyzed based on the use of "internal standards" 5 that characterize some aspects of the system's behavior, such as technical variability, as presented elsewhere ${ }^{6,7}$. The two-step normalization procedure and the Associative analysis functions are implemented in MATLAB (MathWorks, MA) and available from authors upon request. Functional analysis of identified genes was performed with Ingenuity Pathway Analysis (IPA; Ingenuity System). The sequencing data has been deposited in the European Nucleotide Archive under the accession number PRJEB33753.

\section{QUANTIFICATION AND STATISTICAL ANALYSIS}

All data are presented as mean \pm SD. Statistical comparisons were performed using GraphPad Prism 7.0 software. Data were compared using unpaired two-tailed t test, one-way or two-way ANOVA. Statistical significance was set at $p<0.05$. The numbers of independent replicates $(n)$ are reported in the figure legends.

\section{REFERENCES}

1. Reese, T. et al. Helminth infection reactivates latent $\mathrm{y}$-herpesvirus via cytokine competition at a viral promoter. Science 345, 573-577 (2014).

2. Weck, K. E. et al. Murine $\mathrm{Y}$-herpesvirus 68 causes severe large-vessel arteritis in mice lacking interferon- $\gamma$ responsiveness: A new model for virus-induced vascular disease. Nature medicine 3, 1346-1353 (1997).

3. Hwang, S. et al. Persistent gammaherpesvirus replication and dynamic interaction with the host in vivo. Journal of virology 82, 12498-12509 (2008).

4. Rocke, D. \& Durbin, B. A model for measurement error for gene expression arrays. Journal of 
computational biology : a journal of computational molecular cell biology 8, 557-69 (2001).

5. Dozmorov, I. \& Lefkovits, I. Internal standard-based analysis of microarray data. Part 1: analysis of differential gene expressions. Nucleic acids research 37, 6323-39 (2009).

6. Dozmorov, I. \& Centola, M. An associative analysis of gene expression array data.

Bioinformatics (Oxford, England) 19, 204-11 (2003). 
Table 3. QPCR primers for target genes

\begin{tabular}{|c|c|}
\hline Primers & Sequence \\
\hline Ifnb forward & CAGCTCCAAGAAAGGACGAAC \\
\hline Ifnb reverse & GGCAGTGTAACTCTTCTGCAT \\
\hline Cxcl10 forward & TTAACGTCAGGCCAACAGAG \\
\hline Cxcl10 reverse & GAGGGAAACCAGGAAAGATAGG \\
\hline Isg15 forward & CAGGACGGTCTTACCCTTTCC \\
\hline Isg15 reverse & AGGCTCGCTGCAGTTCTGTAC \\
\hline Isg20 forward & CCATGGACTGTGAGATGGTG \\
\hline Isg20 reverse & CTCGGGTCGGATGTACTTGT \\
\hline Gapdh forward & GGGTGTGAACCACGAGAAATA \\
\hline Gapdh reverse & GTCATGAGCCCTTCCACAAT \\
\hline Mgst1 forward & CTGACGAGAAGGTGGAACG \\
\hline Mgst1 reverse & AGATTCTGAAGTGCATGAGGG \\
\hline Gsr forward & CACCGAGGAACTGGAGAATG \\
\hline Gsr reverse & ATCTGGAATCATGGTCGTGG \\
\hline Slc7a11 forward & TGGGCTACGTACTGACAAAC \\
\hline Slc7a11 reverse & AAAGATCGGGACTGCTAATGAG \\
\hline Gstm1 forward & CTATGATACTGGGATACTGGAACG \\
\hline Gstm1 reverse & ACTTCTCATTCAGCCACTGG \\
\hline Gclm forward & AATCAGCCCCGATTTAGTCAG \\
\hline Gclm reverse & CGATCCTACAATGAACAGTTTTGC \\
\hline Cd36 forward & GCGACATGATTAATGGCACAG \\
\hline Cd36 reverse & GATCCGAACACAGCGTAGATAG \\
\hline
\end{tabular}

